\title{
Comparison of Design Guidelines for Hot-Rolled I-Shaped Steel Compression Members according to AISC 360-16 and EC3
}

\author{
S. Pinarbasi $(\mathbb{D}$, T. Genc, E. Akpinar, and F. Okay \\ Department of Civil Engineering, Kocaeli University, İzmit, Kocaeli 41380, Turkey \\ Correspondence should be addressed to S. Pinarbasi; sevalp@gmail.com
}

Received 20 September 2019; Revised 19 May 2020; Accepted 6 July 2020; Published 28 July 2020

Academic Editor: Michael Yam

Copyright ( $\odot 2020$ S. Pinarbasi et al. This is an open access article distributed under the Creative Commons Attribution License, which permits unrestricted use, distribution, and reproduction in any medium, provided the original work is properly cited.

\begin{abstract}
Thirty-six years after its publication, Turkish Building Code for Steel Structures was replaced with a more rational specification, Specification of Design and Construction of Steel Structures (SDCSS), which was prepared almost entirely based on the current American steel design specification (AISC 360-16). European steel design specification (EC3) is also widely used in Turkey for the design of steel structures constructed with the collaboration of Turkish and European companies. It is essential for a steel designer using both SDCSS and EC3 to comprehend the basic differences between these specifications. This study aims to compare the design guidelines defined in AISC 360-16 (so in SDCSS) and EC3 for rolled I-shaped steel members subjected to axial compression thoroughly. For various steel grades, member lengths, and 153 different European I/H sections, design buckling resistances and design compressive strengths are computed and compared. It is shown that there are at most $3 \%$ difference between the effective areas computed using both specifications. It is highly recommended that the change of cross section class be allowed while calculating design buckling resistances. For the studied sections and steel grades, the resistance-to-strength ratios are found to be as high as 1.24 but not smaller than 0.907 .
\end{abstract}

\section{Introduction}

In Turkey, the Building Code for Steel Structures (BCSS) [1], which was based on the allowable stress method, was used for more than three decades in the design of steel structures. Realizing that BCSS has fallen behind most modern design specifications since it has not been updated regularly to reflect the changes in technology and design practice as well as to incorporate the advances in the state of knowledge, the Turkish Ministry of Environment and Urbanisation led to the development of a new up-to-date and rational specification for steel design. Prepared almost entirely based on the current version of the American steel design specification, i.e., the Specification for Structural Steel Buildings (AISC 360-16) [2], the Specification of Design and Construction of Steel Structures (SDCSS) [3] was published in 2016 and superseded BCSS. Since many steel structures constructed in Turkey and in different countries of Europe have been designed with the collaboration of Turkish and European design companies, European steel design specification,
Eurocode 3: Design of Steel Structures (shortly EC3) [4], has also been widely used in Turkey, especially before the publication of SDCSS. The use of EC3 in Turkey is known to continue particularly in the design of special steel structures. For a steel designer who uses both SDCSS and EC3, it is essential to comprehend the basic differences between SDCSS (or AISC 360-16) and EC3 in terms of their design rules and safety levels.

As pointed out by Bjorhovde [5], many studies have been conducted on the strength and stability of steel compression members after the pioneering work of Euler in 1744. The "classical studies of Euler, Tredgold, Tetmajer, Considere, Engesser, von Karman, Shanley, and others until today" [5] have been accompanied by extensive numerical and analytical works. The design guidelines given in current specifications (such as those handled in this study) have been developed based on these valuable research studies. Considered as a landmark study, Bjorhovde [6] tested numerous concentrically loaded steel columns with different crosssectional shapes, steel grades, and residual stress patterns. 
The comprehensive database developed by Bjorhovde [6] for column strength curves pointed out the strong dependence of column strengths to the section shape, steel grade, and manufacturing process. According to Ziemian [7], many other researchers confirmed the findings of Bjorhovde [6]. Considering the wide variability of the column curves, three strength curves, commonly called SSRC (Structural Stability Research Council) column strength curves, were developed by subdividing the band-shaped database obtained by Bjorhovde [6] to obtain rational and reliable column strength criteria. SSRC column curves were developed considering the effects of the (i) member length, (ii) shape and dimensions of the cross section, (iii) mechanical properties of the steel used in the production, (iv) magnitude and distribution of the residual stresses, (v) magnitude and shape of the initial out-of-straightness of the member, and (vi) restraints at the ends of the member. Basic SSRC column curves assumed an initial out-of-straightness of 1/1000 of the column length. Taking the initial out-of-straightness as the mean value of $1 / 1470$ of the column length, Bjorhovde [6] also developed three additional column curves. Expressed slightly in a different form, the column curve used in AISC $360-16$ is indeed identical to one of the curves derived by Bjorhovde [6]. Multiple column curves were also developed in Europe based mostly on the research studies conducted in European universities. According to Ziemian [7], "the single largest group of such column tests is probably the more than 1000 tests that were conducted at a number of European universities and laboratories, as well as a number of tests on heavy shapes at Lehigh University, under the auspices of the European Convention for Constructional Steelwork (ECCS)." Similar to the SSRC curves, the ECCS curves were also derived by taking the maximum permissible value of the initial out-of-straightness as equal to $1 / 1000$ of the member length. The ECCS curves were later adopted, in some modified form, to EC3 as the basic column design curves. Fukumoto and Itoh [8] evaluated both ECCS and SSRC multiple column curves by using the results of 1665 column tests conducted in European countries, Japan, and North America.

American and European steel design codes have already been compared in the literature by a number of studies. However, since the scopes of both documents are rather wide, comparisons have usually been made for some particular topics. Kameski [9] compared the British Standard BS 5950, which can be accepted as an earlier version of EC3, and 1986 version of American steel design specification (AISCLRFD) in view of gravity load combinations, cross section classifications, and basic design guidelines for steel beams, columns, and beam-columns. In the research, weight versus height curves were plotted for some particular W and UC sections and steel grades. Topkaya and Şahin [10] compared the fundamental limit states defined in the 2005 version of AISC 360 specification (i.e., AISC 360-05) and EC3. As far as the design of compression members is concerned, they only compared the column strength curves for steel members that do not have slender-element or Class 4 sections. Yong et al. [11] compared the design approaches given in AISC 360-05 and EC3 for steel beam-columns. They considered only members that do not have slender-element or Class $4 \mathrm{sec}$ tions and compared only the column buckling curves for members subjected to uniaxial compression. Maiorana and Pellegrino [12] compared the design rules given in EC3 for bolted connections in steel bridges with those given in the codes of Italy, the United States, Canada, Australia, and Japan. Gresnight [13] compared the design rules given in EC3 for fillet welds with those given in the 2010 version of AISC 360 specification (AISC 360-10) and the Swedish Code published in 1997. A modification was also proposed in the research to improve the design resistance of the fillet welds used particularly in high-strength steel components. Bakhoum et al. [14] compared both actions (loads) and resistances (strengths) of structural steel, reinforced concrete, and composite members according to the design building codes of the United States, Europe, and Egypt. In this study, design compression resistances (EC3) are compared with design compressive strengths (AISC 360-10) for only a single European rolled section, IPE 300. In a recent research, Galishnikova and Gebre [15] compared the design curves defined in American (AISC 360-10), European (EC3), and Russian (SNIP) specifications for laterally unbraced beams. Some other researchers compared the earlier versions of the American steel design codes with the codes of other countries. As an example, just before the publication of the second version of the LRFD Specification for Structural Steel Building in the USA in 1999, Galambos [16] published a study which compared the first (1993) version of the LRFD Specification with the Canadian and Mexican standards published in 1995 and 1987, respectively. Special emphasis was given to the design rules for steel columns, beams, beamcolumns, and plates. Similarly, Loorits and Talvik [17] compared the lateral-torsional buckling resistances of steel members computed using EC3 and SNIP codes for typical I and $\mathrm{H}$ sections. The book by Bernuzzi and Cordova [18], named Structural Steel Design to Eurocode 3 and AISC Specification, is also worth mentioning in this review in that it summarizes the basic design principles given in both EC3 and AISC 360-10 specifications and presents several design examples. However, Bernuzzi and Cordova [18] seem to remain the comparison of the design rules defined in both specifications mostly to the reader and presented limited examples. As an example, Chapter 6 in [18], where the design of compression members is reviewed, contains only a single example and does not give detailed information about the design of compression members with slender-element or Class 4 sections.

The current version of the American steel design specification (AISC 360-16) was published in 2016 and superseded its 2010 version (AISC 360-10). Since American steel design specifications have been updated regularly, roughly every five years, the design rules do not change drastically in the revised documents. When AISC 360-16 and AISC 360-10 are compared, one can see that the design guidelines for I-shaped compression members with nonslender-element sections have remained the same in the revised specification. On the other hand, the design rules for members with slender-element cross sections have changed completely. The Q-factor approach used in 
AISC 360-10 was replaced in AISC 360-16 with the effective width approach. We have found that, among the steel sections widely used in Turkey and Europe, there are several sections with slender elements. This study takes the revised design guidelines into account for members with slender-element sections in the current American steel design specification.

The main objective of this study is to identify thoroughly the basic differences between the design guidelines given in the current American (so Turkish) and European steel design specifications (AISC 360-16 (so in SDCSS) and EC3) for I-shaped compression members and compare the safety margins of two specifications for various steel sections, member lengths (and slendernesses), and steel grades. Similar studies in the literature were based on earlier versions of the American specification (mostly AISC 360-05 or AISC 360-10) and examined only the design buckling curves and/or compared the design capacities for a limited number of steel sections and grades. Most of these studies also excluded members with slender-element/Class 4 sections. In this study, special emphasis is given to the compression members the design of which should take the effect of local buckling into consideration. The effective cross-sectional areas and member capacities of such members are computed and compared using the recently updated guidelines in AISC 360-16. To the limited knowledge of the authors, such a comparison has not been done in the literature yet. The Clause 5.5.2(10) in EC3 which excludes the use of allowance defined in Clause 5.5.2(9) for the treatment of Class 4 sections as Class 3 sections as long as the maximum design compressive stress in the part is sufficiently small, when verifying the design buckling resistance of member is also evaluated in the study explicitly. In capacity comparisons, jumbo sections with flange thicknesses much larger than $40 \mathrm{~mm}$ are also studied. Both specifications require a reduction in nominal yield strengths for these special sections. Furthermore, EC3 does not define any buckling curve for some of these jumbo sections. In this study, the member capacities are calculated using reduced yield strength values and the buckling curve recommended by a recent study in the literature [19]. This study also takes into account the fact that the studied specifications define different values for elasticity modulus of structural steel (200 GPa in AISC 36016 whereas $210 \mathrm{GPa}$ in EC3).

Comparison of the design rules given for rolled I-shaped compression members for a wide range and large number of European sections including jumbo sections which have reduced yield strengths and may have different buckling curves, assessment of the differences between the currently revised guidelines in AISC 360-16 for the design of members with slender-element sections and the guidelines in EC3 for members with Class 4 sections, computation of capacity ratios for all studied sections, steel grades, and member lengths, evaluation of the Clause 5.5.2(10) in EC3 for members with Class 4 sections, and computation of the critical buckling lengths at which the local buckling effects can be ignored in member capacity calculations are believed to be the main contributions of this study to the current state of the research on the examined subject.
In the study, the design buckling resistances and design compressive strengths are computed and compared for $39 \mathrm{I}$ (IPE and IPN), 72 HE (HEA, HEB, and HEM), and 42 HD sections, which are widely used in Turkish steel construction, for steel grades S235, S275, S355, and/or S460. Among the 153 sections examined in the study, eight IPE, seven HEA, four HEB, and two HEM sections are found to have slender and/or Class 4 webs when the steel grade is S355 and two HD sections are found to have slender and/or Class 4 flanges when the steel grade is S460. For these 23 sections, the effective cross-sectional areas are computed using both specifications and the results are compared. While computing the design buckling resistances of the members with Class 4 sections, the change in section classification is allowed when the member length exceeds a critical length. For all members with Class 4 sections, these critical lengths are also determined and listed.

\section{Materials and Methods}

2.1. Steel Sections and Grades Examined in the Study. Table 1 lists the hot-rolled I and $\mathrm{H}$ sections which are widely used in Turkey and Europe and which are examined in the scope of the study. As shown in the table, from 153 European sections studied, 39 sections have I (IPE and IPN), 72 sections have HE (HEA, HEB, and HEM), and 42 sections have HD shapes. In view of common design practices in Turkey, three widely used steel grades, S235, S275, and S355, are considered for the studied I and HE sections. Similarly, three different steel grades, S275, S355, and S460, are taken into consideration for the studied HD sections.

Table 1 also lists the nominal values of yield strengths $\left(F_{\mathrm{y}}\right)$ for all steel grades considered in the study, which may vary from one section to another for a specified steel grade depending on the flange thickness of the section. Even though SDCSS comprises almost the same design principles as in AISC 360-16, the nominal values of the yield and ultimate strengths for structural steel given in SDCSS are identical to those given in EC3 since European steel products are used in steel construction in Turkey. Table 2.1A in SDCSS, which lists the nominal values of yield stresses for hot-rolled structural steels, is identical to Table 3.1 in EC3.

Clause 3.2.1(1) in EC3 allows the use of the simplification given in Table 3.1 for the nominal value of yield strength for structural steel. According to this simplification, $F_{\mathrm{y}}$ can be taken as constant if the nominal thickness $(t)$ of the element does not exceed $40 \mathrm{~mm}$. The value of $F_{\mathrm{y}}$ reduces slightly, yet remains constant when $t$ exceeds $40 \mathrm{~mm}$. It is to be noted that Table 3.1 in EC3 can be used only when $t$ is smaller than $80 \mathrm{~mm}$. Since the flange thickness of none of the studied I or HE sections exceeds $40 \mathrm{~mm}$, it is decided to take their $F_{\mathrm{y}}$ values from Table 3.1 in EC3, as shown in Table 1. On the other hand, there are some heavy sections with flange thickness exceeding $80 \mathrm{~mm}$ among the studied HD sections. For this reason, $F_{\mathrm{y}}$ of HD sections is determined using the Eurocodes referred in Table 3.1 of EC3 (and in Table 2.1A of SDSCC), i.e., EN 10025-2 [20] for S235, S275, and S355 and EN 10025-4 [21] for S460. 
TABLE 1: European steel sections examined in the study and nominal values of yield strengths (in $\mathrm{N} / \mathrm{mm}^{2}$ ) for different steel grades.

\begin{tabular}{|c|c|c|c|c|c|}
\hline \multirow{2}{*}{ Section } & \multirow{2}{*}{ Section number } & \multicolumn{4}{|c|}{$F_{\mathrm{y}}\left(\mathrm{N} / \mathrm{mm}^{2}\right)$} \\
\hline & & S235 & S275 & S355 & S460 \\
\hline IPE & $80,100,120,140,160,180,200,220,240,270,300,330,360,400,450,500,550,600$ & 235 & 275 & 355 & - \\
\hline IPN & $\begin{array}{c}80,100,120,140,160,180,200,220,240,260,280,300,320,340,360,380,400,450,500 \\
550,600\end{array}$ & 235 & 275 & 355 & - \\
\hline $\begin{array}{l}\text { HEA, HEB, and } \\
\text { HEM }\end{array}$ & $\begin{array}{c}100,120,140,160,180,200,220,240,260,280,300,320,340,360,400,450,500,550,600 \\
650,700,800,900,1000\end{array}$ & 235 & 275 & 355 & - \\
\hline $\mathrm{HD}(t \leq 16 \mathrm{~mm})$ & $260 \times 54.1,260 \times 68.2,320 \times 74.2,320 \times 97.6$ & - & 275 & 355 & 460 \\
\hline $\mathrm{HD}(16<t \leq 40 \mathrm{~mm})$ & $\begin{array}{c}260 \times 93.0,260 \times 114,260 \times 142,260 \times 172,320 \times 127,320 \times 158,320 \times 198,320 \times 245 \\
360 \times 134,360 \times 147,360 \times 162,360 \times 179,360 \times 196,400 \times 187,400 \times 216,400 \times 237 \\
400 \times 262,400 \times 287,400 \times 314\end{array}$ & - & 265 & 345 & 440 \\
\hline $\mathrm{HD}(40<t \leq 63 \mathrm{~mm})$ & $260 \times 225,260 \times 299,320 \times 300,400 \times 347,400 \times 382,400 \times 421,400 \times 463,400 \times 509$ & - & 255 & 335 & 430 \\
\hline $\mathrm{HD}(63<t \leq 80 \mathrm{~mm})$ & $400 \times 551,400 \times 592,400 \times 634$ & - & 245 & 325 & 410 \\
\hline $\begin{array}{l}\mathrm{HD} \\
(80<t \leq 100 \mathrm{~mm})\end{array}$ & $400 \times 677,400 \times 744,400 \times 818$ & - & 235 & 315 & 400 \\
\hline $\begin{array}{l}\text { HD } \\
(100<t \leq 150 \mathrm{~mm})\end{array}$ & $400 \times 900,400 \times 990,400 \times 1086,400 \times 1202,400 \times 1299$ & - & 225 & 295 & 385 \\
\hline
\end{tabular}

Thus, as shown in Table 1, for a specified steel grade, six different sets of $F_{y}$ values are used for $\mathrm{HD}$ sections. It is worth noting that even though the nominal values of yield strengths for structural steel given in SDCSS are identical to those given in EC3, the design values of elasticity and shear modulus $\left(E=200,000 \mathrm{~N} / \mathrm{mm}^{2}, G=77,200 \mathrm{~N} / \mathrm{mm}^{2}\right.$, respectively) are the same as those given in AISC 360-16, rather than in EC3, which define them as $E=210,000 \mathrm{~N} / \mathrm{mm}^{2}$ and $G=81,000 \mathrm{~N} / \mathrm{mm}^{2}$.

2.2. Design of Rolled I-Shaped Compression Members according to AISC 360-16 and SDCSS. AISC 360-16 and SDCSS define two design methodologies for the verification of strength limit states: Load and Resistance Factor Design (LRFD) and Allowable Strength Design (ASD). Since the design philosophy of LRFD is comparable to that used in EC3, only the design principles for the LRFD method are reviewed and used in this study. In the LRFD approach, the fundamental requirement is that the design strength $\left(\phi R_{n}\right)$ of a structural component at least be equal to its required strength $\left(R_{u}\right)$, which should be determined from the load combinations specifically defined for this approach. The design strength $\left(\phi R_{n}\right)$ of any component can be computed by multiplying its nominal strength $\left(R_{n}\right)$ with a strength reduction factor called resistance factor $(\phi)$. For all applicable limit states, $R_{n}$ and $\phi$ are specified in Chapters D through $\mathrm{K}$ in AISC 360-16 and in Chapters 7 through 14 in SDCSS. The design of members for compression is addressed in Chapter $\mathrm{E}$ in AISC 360-16 and Chapter 8 in SDCSS. Section E1 in AISC 360-16 and Section 8.1 in SDCSS define a single resistance factor $\left(\phi_{c}=0.90\right)$ for all limit states applicable to axially compressed members.

According to the Table User Note E1.1 in AISC 360-16, there are at most three applicable limit states based on which the design compressive strength of a doubly-symmetric I-shaped member is determined; (i) flexural buckling, (ii) torsional buckling, and (iii) local buckling. The last limit state is valid only for compression members with slenderelement sections. As far as the members subject to axial compression are concerned, AISC 360-16 and SDCSS classify the sections of the members for local buckling as either nonslender-element or slender-element sections. According to Section B4.1 of AISC 360-16 and Section 5.4 of SDCSS, a member subject to axial compression is classified as a slender-element member if the width-to-thickness ratio $(b / t=\lambda)$ of at least one of its compression elements exceeds the limiting width-to-thickness ratio $\left(\lambda_{\mathrm{r}}\right)$ defined in Table B4.1 and Table 5.1A in the same specifications, respectively. Accordingly, a rolled I-shaped compression member has a slender-element section if it satisfies the following equation:

$$
\begin{aligned}
& \lambda_{\mathrm{f}}=\left(\frac{b}{t}\right)_{\mathrm{f}}=\frac{\left(b_{\mathrm{f}} / 2\right)}{t_{\mathrm{f}}}>\lambda_{\mathrm{rf}}=0.56 \sqrt{\frac{E}{F_{\mathrm{y}}}} \\
& \text { and } / \text { or } \lambda_{\mathrm{w}}=\left(\frac{b}{t}\right)_{\mathrm{w}}=\frac{h}{t_{\mathrm{w}}}>\lambda_{\mathrm{rw}}=1.49 \sqrt{\frac{E}{F_{\mathrm{y}}}} .
\end{aligned}
$$

where $\lambda_{\mathrm{f}}$ and $\lambda_{\mathrm{w}}$ are the width-to-thickness ratios for flanges and web, respectively; $\lambda_{\mathrm{rf}}$ and $\lambda_{\mathrm{rw}}$ are the corresponding limiting width-to-thickness ratios; $b_{\mathrm{f}}$ and $t_{\mathrm{f}}$ are the width and thickness of the flanges of the section, respectively; $h$ is "flat" width of the web, which can be computed by subtracting the fillet at each flange from the clear distance between the flanges; $t_{\mathrm{w}}$ is the web thickness; $F_{\mathrm{y}}$ is the specified minimum yield stress of the steel being used; and $E$ is the modulus of elasticity of the steel $(E=200 \mathrm{GPa})$.

According to Sections E3 and E4 in AISC 360-16 and Section 8.2 in SDCSS, for compression members without slender-element sections, the nominal compressive strength $P_{\mathrm{n}}$ shall be determined by multiplying the critical stress $F_{\mathrm{cr}}$ with its gross cross-sectional area $A_{\mathrm{g}}$ :

$$
P_{\mathrm{n}}=F_{\mathrm{cr}} A_{\mathrm{g}} \text {. }
$$

The critical stress should be determined as follows: 


$$
\begin{aligned}
& \text { when } \frac{F_{\mathrm{y}}}{F_{\mathrm{e}}} \leq 2.25, \quad F_{\mathrm{cr}}=\left[0.658^{F_{\mathrm{y}} / F_{\mathrm{e}}}\right] F_{\mathrm{y}} ; \\
& \text { when } \frac{F_{\mathrm{y}}}{F_{\mathrm{e}}}>2.25, \quad F_{\mathrm{cr}}=0.877 F_{\mathrm{e}} .
\end{aligned}
$$

where $F_{\mathrm{e}}$ is the elastic buckling stress, which can be taken as the lowest value obtained using equation (4) for the limit states of flexural buckling and equation (5) for the limit state of torsional buckling:

$$
\begin{aligned}
& F_{\mathrm{e}}=\frac{\pi^{2} E}{\left(L_{\mathrm{c}} / i\right)^{2}}, \\
& F_{\mathrm{e}}=\left(\frac{\pi^{2} E C_{\mathrm{w}}}{\left(L_{\mathrm{c} z}\right)^{2}}+G J\right) \frac{1}{I_{x}+I_{y}} .
\end{aligned}
$$

In equation (4), $L_{\mathrm{c}} / i$ is the smaller of the member slendernesses for flexural buckling about $x$ (strong) and $y$ (weak) axes, $L_{\mathrm{c}}$ is the effective length of the member for the critical flexural buckling mode, $i$ is the radius of gyration of the cross section about the related principal axis. It is to be noted that, in this study, instead of the symbol $r$, which is used in AISC 360-16, $i$ is used for radius of gyration, since both EC3 and SDCSS use the latter symbol. In equation (5), $C_{\mathrm{w}}$ and $J$ are, respectively, the warping and torsional constants of the cross section, $I_{x}$ and $I_{y}$ are the moments of inertia about principal axes, $L_{c z}$ is the effective length of the member for buckling about longitudinal axis $(z), G$ is the shear modulus of elasticity of the steel being used $(G=77.2 \mathrm{GPa})$. In this study, the effective member lengths are assumed to be equal to the actual member lengths, i.e., $L_{c x}=L_{c y}=L_{c z}=L$ for all applicable buckling modes. For this reason, it is sufficient to consider flexural buckling about weak axis and torsional buckling.

According to Section E7 in AISC 360-16 and Section 8.5 in SDCSS, while calculating the nominal compressive strength $P_{\mathrm{n}}$ of a compression member with a slender-element section, the interaction of the limit state of member buckling (i.e., flexural or torsional buckling) with local buckling has to be taken into consideration as follows:

$$
P_{\mathrm{n}}=F_{\mathrm{cr}} A_{\mathrm{e}},
$$

where $F_{\mathrm{cr}}$ is the critical stress determined using equation (3) and $A_{\mathrm{e}}$ is the effective area of the cross section computed using the reduced effective areas of slender elements. For I-shaped sections, the effective width $b_{\mathrm{e}}$ of a slender element should be determined as follows:

$$
\begin{aligned}
& \text { when } \lambda \leq \lambda_{\mathrm{r}} \sqrt{\frac{F_{\mathrm{y}}}{F_{\mathrm{cr}}}}, \quad b_{\mathrm{e}}=b ; \\
& \text { when } \lambda>\lambda_{\mathrm{r}} \sqrt{\frac{F_{\mathrm{y}}}{F_{\mathrm{cr}}}}, \quad b_{\mathrm{e}}=b\left(1-c_{1} \sqrt{\frac{F_{\mathrm{el}}}{F_{\mathrm{cr}}}}\right) \sqrt{\frac{F_{\mathrm{el}}}{F_{\mathrm{cr}}}},
\end{aligned}
$$

where $b$ is the width of the slender element and equal to $b_{\mathrm{f}} / 2$ and $h$ for the flanges and web of a rolled I-shaped member, respectively, $\lambda$ is the width-to-thickness ratio for the slender element, and $\lambda_{\mathrm{r}}$ is the limiting width-to-thickness ratio as defined in equation (1), and $F_{\mathrm{el}}$ is the elastic local buckling stress for the slender element, which can be computed using the following equation:

$$
F_{\mathrm{el}}=\left(c_{2} \frac{\lambda_{\mathrm{r}}}{\lambda}\right)^{2} F_{\mathrm{y}},
$$

where $c_{1}$ in equation (7) and $c_{2}$ in equation (8) are called effective width imperfection adjustment factors and should be determined from Table E7.1 in AISC 360-16 and Table 8.2 in SDCSS. These tables give the values of $c_{1}$ and $c_{2}$ as 0.22 and 1.49 for the flanges and as 0.18 and 1.31 for the web of a member with I-shaped cross section. It is worth noting that equation (8) was not correct in the first version of SDCSS published in 2016 [3]. This error was corrected in the updated version of the specification published in 2018 [22]. In this study, this revised version of the Turkish specification is used.

From equation (7), it can be inferred that the effective width of a slender element can be equal to its full width even when its width-to-thickness ratio $(\lambda)$ is larger than the limiting width-to-thickness ratio $\left(\lambda_{\mathrm{r}}\right)$. In other words, an element classified as a slender element according to Section B4.1 in AISC 360-16 and Section 5.4 in SDCSS may not be treated as a slender element if the critical stress of the member is sufficiently small. It can be realized that the element classification defined in AISC 360-16 is based on that $F_{\mathrm{cr}}=F_{\mathrm{y}}$, i.e., on the assumption that local buckling occurs before member buckling; however, in most cases, due to the slenderness of the member, flexural or torsional buckling occurs at critical stresses well below the yield stress. Thus, equation (7) can be thought as a "second check" for an element which has been classified as a slender element in the "first check" (equation (1)) to decide whether the interaction of local buckling with member buckling should be considered or can be ignored in the design.

\subsection{Design of Rolled I-Shaped Compression Members} according to EC3. EC3 uses limit state design in conjunction with the partial factor method. According to this design approach, the basic requirement is that the design resistance of a member at least be equal to the design value of the action effect. The partial factors to be used in resistance calculations are defined in Section 6.1 of EC3, where the value 1.00 is recommended for both partial factors used in the design of uniformly compressed members in buildings $\left(\gamma_{\mathrm{M} 0}\right.$ and $\left.\gamma_{\mathrm{M} 1}\right)$. In this study, these recommended values are used.

As far as the design of axially compressed members is concerned, two resistance verifications have to be done in ultimate limit states: (i) verification of cross section resistance and (ii) verification of buckling resistance. For both verifications, the cross section of the member must be classified first. Similar to AISC 360-16, EC3 classifies cross sections of steel members based on the width-to-thickness ratios (called $c / t$ ratios in EC3) of their parts that are subjected to compression. Even though four classes are defined in Section 5.5 in EC3, namely, Class 1, Class 2, Class 3, and 
Class 4 , the design equations used in the verification of both cross section and buckling resistances of compression members are identical unless the member has a Class 4 section. For this reason, in this study, the sections classified as Class 1, Class 2, or Class 3 are named as "non-Class 4" sections.

In EC3, Class 4 sections are defined as the sections that have at least one compression part with a $c / t$ ratio exceeding the maximum width-to-thickness ratios given in Table 5.2 for Class 3 sections. For the flanges and web of a rolled I-shaped member subject to uniform compression, the limiting values of $c / t$ ratio for Class 3 cross sections are given in Table 5.2 as $14 \varepsilon$ and $42 \varepsilon$, respectively, where $\varepsilon$ is equal to the square root of the ratio of $235 / F_{\mathrm{y}}$. It is worth noting that, in this study, instead of the symbol $f_{\mathrm{y}}$, which is used in EC3, $F_{\mathrm{y}}$ is used for the nominal value of the yield strength for the structural steel, since both AISC 360-16 and SDCSS use the latter symbol. It should also be noted that while calculating $\varepsilon$, the unit of $F_{y}$ must be $\mathrm{N} / \mathrm{mm}^{2}(\mathrm{MPa})$. Thus, a rolled I-shaped member under uniform compression has a Class 4 section if

$$
\begin{aligned}
\left(\frac{c}{t}\right)_{\mathrm{f}} & =\frac{\left(\left(b_{\mathrm{f}}-t_{\mathrm{w}}-2 r\right) / 2\right)}{t_{\mathrm{f}}}>14 \varepsilon, \\
\operatorname{or}\left(\frac{c}{t}\right)_{\mathrm{w}} & =\frac{d-2 t_{\mathrm{f}}-2 r}{t_{\mathrm{w}}}>42 \varepsilon, \\
\text { where } \varepsilon & =\sqrt{\frac{235}{F_{\mathrm{y}}}} .
\end{aligned}
$$

In equation (9), $(c / t)_{\mathrm{f}}$ and $(c / t)_{\mathrm{w}}$ are the width-tothickness ratios for flanges and web, respectively; $r$ is the radius of root fillet and $d$ is the depth of the cross section. Again, instead of the symbol $h$, which is used in EC3, $d$ is used for the section depth in this study. Comparison of equations (1) and (9) shows that while the definition of the width-to-thickness ratio for the web of a rolled I-shape is identical in both specifications, that for the flanges is different; EC3 uses the "flat" width whereas AISC uses the full width of the half flange.

Clause 5.5.2(9) in EC3 allows the treatment of Class 4 sections as Class 3 sections (i.e., as "non-Class 4 sections") provided that "the width-to-thickness ratios are less than the limiting proportions for Class 3 obtained from Table 5.2 when $\varepsilon$ is increased by" the square root of $F_{\mathrm{y}} / \sigma_{\text {com,Ed }}$, where $\sigma_{\text {com,Ed }}$ is the "maximum design compressive stress in the part." However, Clause 5.5.2(10) excludes the use of this allowance when verifying the design buckling resistance of the member. It is believed that the allowance provided in Clause 5.5.2(9) in EC3 resembles the "second check" done in AISC 360-16 (equation (7)) for compression members with slender-element sections.

Recalling that in this study, the partial factor for the cross section resistance is taken as recommended (i.e., $\gamma_{\mathrm{M} 0}=1.00$ ), the design resistance of the cross section of a member subject to uniform compression $\left(N_{c, R d}\right)$, defined in Section 6.2.4 in EC3, can be expressed as follows:

$$
N_{\mathrm{c}, \mathrm{Rd}}=A^{*} F_{\mathrm{y}},
$$

where

$$
\begin{array}{ll}
A^{*}=A_{\mathrm{g}}, & \text { for "non-Class } 4 \text { " cross sections, } \\
A^{*}=A_{\mathrm{e}}, & \text { for Class } 4 \text { cross sections. }
\end{array}
$$

Even though the symbols $A$ and $A_{\text {eff }}$ are used in EC3 for gross and effective cross-sectional areas, respectively, the use of the symbols $A_{\mathrm{g}}$ and $A_{\mathrm{e}}$, as in equations (2) and (6), are preferred in the study for consistency. From equation (10), it can be seen that the cross section resistance is equal to the yield load of the member unless the member has Class 4 section. For members with Class 4 sections, the cross section resistance has to be reduced due to the local buckling effects. The effective cross-sectional area of a member with a Class 4 section should be calculated using another part of Eurocode 3, EN 1993-1-5: Plated structural elements [23]. According to Section 4.4 of EN 1993-1-5, the effective area of a flat compression part should be computed by multiplying its gross cross-sectional area with a reduction factor $\rho$, which accounts for plate buckling. The reduction factors given in EN 1993-1-5 for the flanges and web ( $\rho_{\mathrm{f}}$ and $\rho_{\mathrm{w}}$, respectively) of a rolled I-shaped member subject to uniform compression can be expressed as follows:

$$
\begin{array}{r}
\rho_{\mathrm{f}}=\frac{\bar{\lambda}_{p \mathrm{f}}-0.188}{\bar{\lambda}_{p \mathrm{f}}^{2}} \leq 1.0, \quad \text { for } \bar{\lambda}_{p \mathrm{f}}>0.748, \\
\rho_{\mathrm{f}}=1.0, \quad \text { for } \bar{\lambda}_{p \mathrm{f}} \leq 0.748, \\
\rho_{\mathrm{w}}=\frac{\bar{\lambda}_{p \mathrm{w}}-0.22}{\bar{\lambda}_{p \mathrm{w}}^{2}} \leq 1.0, \quad \text { for } \bar{\lambda}_{p \mathrm{w}}>0.673, \\
\rho_{\mathrm{w}}=1.0, \quad \text { for } \bar{\lambda}_{p \mathrm{w}} \leq 0.673,
\end{array}
$$

where

$$
\begin{gathered}
\bar{\lambda}_{p \mathrm{f}}=\frac{(c / t)_{\mathrm{f}}}{18.6 \varepsilon}, \\
\bar{\lambda}_{p \mathrm{w}}=\frac{(c / t)_{\mathrm{w}}}{56.8 \varepsilon} .
\end{gathered}
$$

According to Section 6.3.1 in EC3, the design buckling resistance $\left(N_{\mathrm{b}, \mathrm{Rd}}\right)$ of a compression member should be determined using the following equation:

$$
N_{\mathrm{b}, \mathrm{Rd}}=\chi A^{*} F_{\mathrm{y}}
$$

where the value of the reduction factor $\chi$ for the appropriate nondimensional slenderness $\bar{\lambda}$ should be determined from the relevant buckling curve as follows:

$$
\begin{gathered}
\quad \chi=\frac{1}{\Phi+\sqrt{\Phi^{2}-(\bar{\lambda})^{2}}} \text {, where } \Phi=0.5\left[1+\alpha(\bar{\lambda}-0.2)+(\bar{\lambda})^{2}\right], \\
\text { with } \bar{\lambda}=\sqrt{\frac{A^{*} F_{\mathrm{y}}}{N_{\mathrm{cr}}}}
\end{gathered}
$$

In general, five buckling curves are defined in EC3, namely, $a_{0}, a, b, c$, and $d$. The appropriate buckling curve to 
be used in the design of a compression member should be selected from Table 6.2 in EC3 based on the shape and dimensions of the cross section, buckling axis, and steel grade. It should be noted that the conventions used in EC3 for member axes are different than those in AISC 360-16 and SDCSS. For an I-shaped member, $y$ and $z$ axes are defined in EC3 as cross-sectional axis parallel and perpendicular to flanges, respectively. That is, $y$-axis is the strong and $z$-axis is the weak axis of the cross section. Thus, $x$-axis is the axis along the member. In Table 6.2 of EC3, buckling curves are defined only for buckling modes about $y$ - or $z$-axis, i.e., only for flexural buckling modes. Clause 6.3.1.4(3) in EC3 states that for torsional buckling, "the appropriate buckling curve may be determined from Table 6.2 considering the one related to $z$-axis." Since all member buckling lengths are assumed to be equal to the member length $\left(L_{c y}=L_{c z}=L_{c x}=L\right)$ in this study, it is sufficient to determine only the buckling curves related to the weak axis.

From Table 6.2 in EC3, it can be seen that for a rolled I-shaped member, the appropriate buckling curve related to $z$-axis depends on the (i) depth-to-width $\left(d / b_{\mathrm{f}}\right)$ ratio of the cross section, (ii) thickness of the flange $\left(t_{\mathrm{f}}\right)$, and (iii) steel grade. For a rolled I-section with a $d / b_{\mathrm{f}}$ ratio greater than 1.2 and a steel grade of S235, S275, S355, or S420, curve $b$ should be used if $t_{\mathrm{f}}$ does not exceed $40 \mathrm{~mm}$ and curve $c$ should be used if $t_{\mathrm{f}}$ is larger than $40 \mathrm{~mm}$ but smaller than or equal to $100 \mathrm{~mm}$. The corresponding buckling curves for S460 steel grade are $a_{0}$ and $a$, respectively. Table 6.2 in EC3 does not define buckling curves for sections with $d / b_{\mathrm{f}}$ ratio larger than 1.2 and $t_{\mathrm{f}}$ larger than 100. In a recent study, Snijder et al. [19] proposed the use of buckling curve $c$ for S235, S275, S355, or S420 steel grades and buckling curve $b$ for $\$ 460$ or $\$ 500$ steel grades for such heavy sections. In this study, the buckling curves recommended by Snijder et al. [19] are used for heavy HD sections with $d / b_{\mathrm{f}}>1.2$ and $t_{\mathrm{f}}>100$. According to Table 6.2 in EC3, for a rolled I-shaped member with a steel grade of $\mathrm{S} 235, \mathrm{~S} 275, \mathrm{~S} 355$, or $\mathrm{S} 420$ and a section of $d / b_{\mathrm{f}}$ ratio not exceeding 1.2, curve $c$ should be used if $t_{\mathrm{f}}$ does not exceed $100 \mathrm{~mm}$ and curve $d$ should be used if it is larger. The corresponding buckling curves for S460 steel grade are $a$ and $c$, respectively.

The imperfection factor $\alpha$ in equation (16) is defined in Table 6.1 in EC3, which gives the values of $0.13,0.21,0.34$, 0.49 , and 0.76 for buckling curves $a_{0}, a, b, c$, and $d$, respectively. $N_{\mathrm{cr}}$ appearing in equation (16) is defined in Clause 6.3.1.2(1) of EC3 as "the elastic critical force for the relevant buckling mode based on gross cross-sectional properties." From Section 6.3.1.3 in EC3, one can see that EC3 defines elastic critical force $N_{\text {cr }}$ for flexural buckling mode just as AISC 360-16 defines elastic buckling stress $F_{\mathrm{e}}$ (given in equation (4)). In fact, for flexural buckling mode, $N_{\mathrm{cr}}=A_{\mathrm{g}} F_{\mathrm{e}}$. On the other hand, EC3 does not give any design expression for elastic torsional buckling load. In this study, the expression given for elastic torsional buckling load in one of the Eurocode design manuals [24], which, indeed, is identical to the expression defined in AISC 360-16 (given in equation (5)), is used.

It is also to be noted that Clause 6.3.1.2(4) in EC3 allows ignoring the buckling effects if the value of the nondimensional slenderness does not exceed 0.2 or the ratio of the design value of the compression force to the elastic critical force does not exceed 0.04 .

\section{Results and Discussion}

3.1. Comparison of the Basic Design Principles for I-Shaped Compression Members Given in AISC 360-16 (so in SDCSS) and EC3. One of the differences in the design principles for rolled I-shaped compression members given in AISC 360-16 and EC3 is that the design compressive strength $\left(\phi_{\mathrm{c}} P_{\mathrm{n}}\right)$ of a member calculated using AISC $360-16$ is equal to $90 \%$ of its nominal strength $\left(P_{\mathrm{n}}\right)$ whereas the design resistance $\left(N_{\mathrm{b}, \mathrm{Rd}}\right.$ or $N_{\mathrm{c}, \mathrm{Rd}}$ ) of the same member calculated using EC3 is equal to its nominal resistance if the recommended values are used for partial factors $\gamma_{\mathrm{M} 0}$ and $\gamma_{\mathrm{M} 1}$. In other words, while AISC 360-16 considers EC3 ignores understrength.

Another important difference between two specifications is observed on the design values for modulus of elasticity $(E)$ and shear modulus $(G)$ of structural steel. Since the values given in AISC 360-16 are about 5\% smaller than those given in EC3, elastic buckling loads and stresses computed using AISC 360-16 are about 5\% smaller than those computed using EC3. The difference in $E$ is also believed to affect the limiting values given in the specifications for the cross section classification. As an example, for $F_{\mathrm{y}}=355 \mathrm{MPa}$, the limiting width-to-thickness ratio for the web of a rolled I-section is 35.4 (from equation (1)) for AISC 360-16 and 34.2 (from equation (9)) for EC3. For this reason, having a width-to-thickness ratio of 35.0, the web of an IPE300 section is classified as a nonslender-element section according to AISC 360-16 but Class 4 element according to EC3. A similar difference is seen in the limiting width-tothickness ratios for the flanges. An I-section with $F_{\mathrm{y}}=355 \mathrm{MPa}$ is classified to have Class 4 flanges if the widthto-thickness ratio of its flanges exceeds 11.4; on the other hand, it has nonslender flanges provided that the width-tothickness ratio of its flanges is smaller than 13.3. However, it should also be noted that the definitions of width-tothickness ratio for the flanges of an I-section are also different in AISC 360-16 and EC3. Since EC3 uses flat widths of half flanges instead of their gross widths as in AISC 360-16, $c / t$ ratio for the flanges of any I-section is always smaller than its $b / t$ ratio. As an example, the flanges of HD $320 \times 74.2$ section has a $b / t$ ratio of 13.64 but a $c / t$ ratio of 10.82 . Thus, for a steel grade of S355, HD $320 \times 74.2$ section has slender (since $13.64>13.3$ ) but non-Class 4 (since $10.82<11.4$ ) flanges.

For the steel grades and sections considered in the study, Table 2 lists the sections which are classified as slender-element sections according to AISC 360-16 and/or as Class 4 sections according to EC3. It is to be noted that none of the studied IPN sections have slender or Class 4 elements. For this reason, Table 2 does not include any IPN section. As shown in the table, most of the sections classified as slenderelement sections are also classified as Class 4 sections. All I and HE sections appearing in Table 2 have slender and/or Class 4 webs while two HD sections given in the table have slender and/or Class 4 flanges. None of the studied sections 
TABLE 2: The numbers of slender-element sections according to AISC 360-16 and Class 4 sections according to EC3 for the studied steel grades.

\begin{tabular}{|c|c|c|c|c|c|c|c|c|c|c|}
\hline & \multicolumn{2}{|c|}{ IPE } & \multicolumn{2}{|c|}{ HEA } & \multicolumn{2}{|c|}{ HEB } & \multicolumn{2}{|c|}{ HEM } & \multicolumn{2}{|c|}{$\mathrm{HD}$} \\
\hline & AISC & EC3 & AISC & EC3 & AISC & EC3 & AISC & EC3 & AISC & EC3 \\
\hline S235 & - & $\begin{array}{l}550 \\
600\end{array}$ & $\begin{array}{c}800 \\
900 \\
1000 \\
\end{array}$ & $\begin{array}{c}800 \\
900 \\
1000 \\
\end{array}$ & 1000 & 1000 & - & - & - & - \\
\hline S275 & $\begin{array}{l}450 \\
500 \\
550 \\
600\end{array}$ & $\begin{array}{l}450 \\
500 \\
550 \\
600\end{array}$ & $\begin{array}{c}800 \\
900 \\
1000\end{array}$ & $\begin{array}{c}650 \\
700 \\
800 \\
900 \\
1000 \\
\end{array}$ & $\begin{array}{c}900 \\
1000\end{array}$ & $\begin{array}{c}900 \\
1000\end{array}$ & - & 1000 & - & - \\
\hline S355 & $\begin{array}{l}330 \\
360 \\
400 \\
450 \\
500 \\
550 \\
600\end{array}$ & $\begin{array}{l}300 \\
330 \\
360 \\
400 \\
450 \\
500 \\
550 \\
600\end{array}$ & $\begin{array}{c}600 \\
650 \\
700 \\
800 \\
900 \\
1000\end{array}$ & $\begin{array}{c}550 \\
600 \\
650 \\
700 \\
800 \\
900 \\
1000\end{array}$ & $\begin{array}{c}800 \\
900 \\
1000\end{array}$ & $\begin{array}{c}700 \\
800 \\
900 \\
1000\end{array}$ & $\begin{array}{c}900 \\
1000\end{array}$ & $\begin{array}{c}900 \\
1000\end{array}$ & $\begin{array}{l}260 \times 54.1 \\
320 \times 74.2\end{array}$ & - \\
\hline S460 & - & - & - & - & - & - & - & - & $\begin{array}{l}260 \times 54.1 \\
320 \times 74.2\end{array}$ & $\begin{array}{l}260 \times 54.1 \\
320 \times 74.2\end{array}$ \\
\hline
\end{tabular}

Italic numbers show sections which are classified as Class 4 sections but nonslender-element sections or vice versa.

is observed to have slender web and flanges simultaneously. Due to the differences in the definitions of limiting width-tothickness ratios in the studied specifications, some I and HE sections, such as IPE550 for S235, HEM1000 for S275, and HEA550 for S355 steel grade (which are written in italic in Table 2), have nonslender-element but Class 4 sections.

Two HD sections (with numbers $260 \times 54.1$ and $320 \times 74.2$ ), both of which are classified as slender-element and Class 4 sections when steel grade is S460, are classified as slender-element sections but non-Class 4 sections for a steel grade of S355. This class variation occurs, as already explained, due to the definition difference in the width-tothickness ratio for the flanges.

Comparison of equation (7) with equations (12) and (13) shows that the design rules given in AISC 360-16 and EC3 for the calculation of effective areas of sections containing slender elements are also different. The expressions given in EC3 depend only on the width-to-thickness ratio of the Class 4 element and steel grade whereas the equation in AISC 36016 also depends on the critical stress $\left(F_{\mathrm{cr}}\right)$, which, in turn, depends on the member slenderness $\left(L_{c} / i\right)$. For this reason, while calculating the design compressive strength of a member with a slender-element section, instead of effective area, the gross area of the cross section can be used if $F_{\mathrm{cr}}$ is sufficiently small and, in other words, if the section is classified as a nonslender-element section in the "second check" (equation (7)). To compare the design equations given in AISC 360-16 and EC3 for effective area calculations, the effective areas (denoted as $A_{\mathrm{e}, \mathrm{AISC}} 360-16$ and $A_{\mathrm{e}, \mathrm{EC} 3}$ ) of each section given in Table 2 are computed using both specifications and the ratios of the effective areas to the gross areas $\left(A_{\mathrm{e}, \mathrm{AISC} 360-16} / A_{\mathrm{g}}\right.$ and $\left.A_{\mathrm{e}, \mathrm{EC} 3} / A_{\mathrm{g}}\right)$ are presented in Table 3. $A_{\mathrm{e}, \mathrm{AISC}}$ 360-16 values are calculated for a small value of member slenderness $\left(L_{\mathrm{c}} / i=1\right)$ so that the minimum values of $A_{\mathrm{e}, \mathrm{AISC} 360-16}$ could be obtained. Since the reduction in cross- sectional area increases with increasing yield strength, the effective areas for I and HE sections are calculated for S355 steel grade and those for HD sections are calculated for $\mathrm{S} 460$ steel grade.

The ratios of the effective areas computed using EC3 to those computed using AISC 360-16 ( $\left.A_{\mathrm{e}, \mathrm{EC} 3} / A_{\mathrm{e}, \mathrm{AISC}} 360-16\right)$ are also presented in Table 3 . As shown in the table, the decrease in gross cross-sectional area increases as the number of the section increases for all studied section groups. As an example, while $A_{\mathrm{e}, \mathrm{EC} 3} / A_{\mathrm{g}}$ is equal to 0.983 for HEA550 section, it drops to 0.880 for HEA1000 section. Similarly, $A_{\mathrm{e}, \mathrm{AISC} 360-16} / A_{\mathrm{g}}$ is equal to 0.996 for IPE330 and to 0.949 for IPE600 section. For all studied sections and steel grades, the maximum decrease in cross-sectional area, about $11 \%$ for AISC $360-16$ and $12 \%$ for EC3, occurs for the compression member with HEA1000 section and S355 steel grade. For members with slender and Class 4 webs, the decrease in cross-sectional area is slightly larger when effective areas are calculated according to EC3, but the maximum difference does not exceed $2 \%$. For the HD sections which have slender/Class 4 flanges, the effective areas computed using AISC 360-16 are a bit smaller, but the difference again is not large (at most 3\%). Thus, it can be concluded that even though different design rules are defined in AISC 360-16 and EC3 for the calculation of effective cross-sectional areas, almost identical results are obtained for all studied sections and steel grades.

It is to be noted that the $A_{\mathrm{e}, \mathrm{AISC}} 360-16 / A_{\mathrm{g}}$ ratios listed in Table 3 actually approaches unity as the member slenderness $\left(L_{\mathrm{c}} / i\right)$ increases. Figure 1 shows how the effective height $\left(h_{\mathrm{e}}\right)$ of HEA1000 section, which has a slender web for S355 steel grade, computed using AISC 360-16 increases towards its gross height as the effective length $\left(L_{\mathrm{c}}\right)$ of the member increases. It can be shown that when $L_{\mathrm{c}}$ approximately is equal to $6.5 \mathrm{~m}, A_{\mathrm{e}, \mathrm{AISC}} 360-16$ becomes equal to $A_{\mathrm{g}}$. In this study, the 
TABLE 3: Comparison of the effective cross-sectional areas of compression members with slender-element sections computed according to AISC 360-16 ( $\left.A_{\mathrm{e}, \mathrm{AISC} 360-16}\right)$ and those with Class 4 sections computed according to EC3 $\left(A_{\mathrm{e}, \mathrm{EC} 3}\right)$.

\begin{tabular}{|c|c|c|c|c|}
\hline Section & Steel grade & $A_{\mathrm{e}, \mathrm{AISC} 360-16} / A_{\mathrm{g}}(\%)$ & $A_{\mathrm{e}, \mathrm{EC} 3} / A_{\mathrm{g}}(\%)$ & $A_{\mathrm{e}, \mathrm{EC} 3} / A_{\mathrm{e}, \mathrm{AISC} 360-16}$ \\
\hline IPE300 & \multirow{8}{*}{ S355 } & 100 & 97.9 & 0.979 \\
\hline IPE330 & & 99.6 & 97.4 & 0.978 \\
\hline IPE360 & & 98.8 & 96.7 & 0.979 \\
\hline IPE400 & & 98.1 & 96.1 & 0.980 \\
\hline IPE450 & & 96.8 & 94.9 & 0.980 \\
\hline IPE500 & & 95.8 & 93.9 & 0.980 \\
\hline IPE550 & & 95.4 & 93.5 & 0.980 \\
\hline IPE600 & & 94.9 & 93.0 & 0.980 \\
\hline HEA550 & \multirow{7}{*}{ S355 } & 100 & 98.3 & 0.983 \\
\hline HEA600 & & 99.0 & 97.2 & 0.982 \\
\hline HEA650 & & 97.7 & 96.1 & 0.984 \\
\hline HEA700 & & 97.2 & 95.5 & 0.983 \\
\hline HEA800 & & 94.3 & 92.8 & 0.984 \\
\hline HEA900 & & 92.2 & 90.7 & 0.984 \\
\hline HEA 1000 & & 89.3 & 88.0 & 0.985 \\
\hline HEB700 & \multirow{4}{*}{ S355 } & 100 & 98.4 & 0.984 \\
\hline HEB800 & & 98.0 & 95.9 & 0.979 \\
\hline HEB900 & & 95.8 & 93.8 & 0.979 \\
\hline HEB1000 & & 93.0 & 91.2 & 0.981 \\
\hline HEM900 & \multirow{2}{*}{ S355 } & 99.1 & 96.6 & 0.975 \\
\hline HEM1000 & & 95.7 & 93.6 & 0.978 \\
\hline HD260 $\times 54.1$ & \multirow{2}{*}{ S460 } & 94.0 & 96.9 & 1.03 \\
\hline $\mathrm{HD} 340 \times 74.2$ & & 94.3 & 96.7 & 1.03 \\
\hline
\end{tabular}

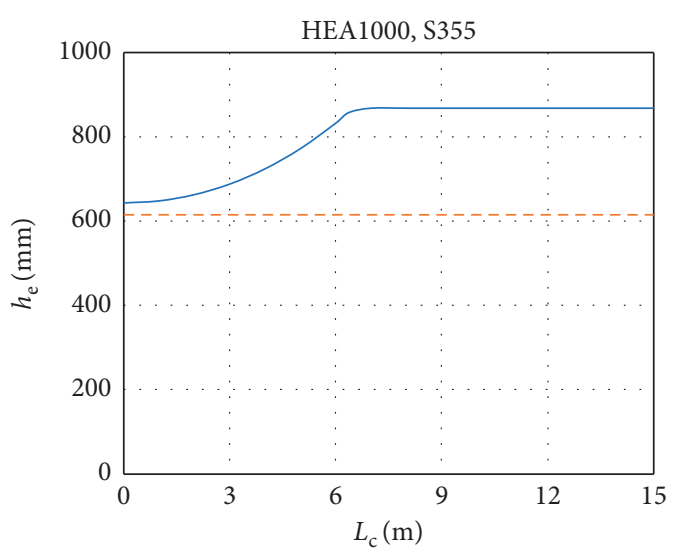

- AISC 360-16

- - EC3-class change not allowed

(a)

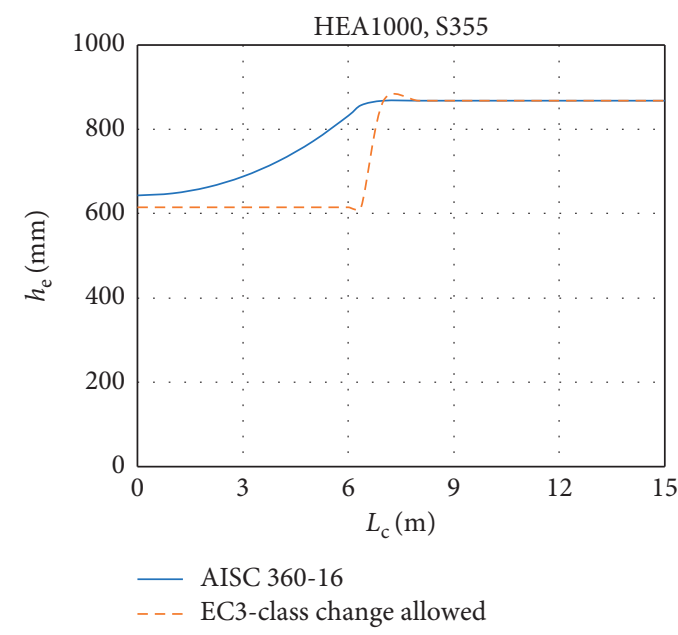

(b)

FIGURE 1: For a steel grade of S355, the variation of effective height $\left(h_{e}\right)$ of HEA1000 section with the effective length $\left(L_{c}\right)$ of the member. The effective heights computed using AISC 360-16 are compared with those computed using EC3 without making the class change allowed in Clause 5.5.2(9) in (a) and with making the class change in (b).

minimum $L_{\mathrm{c}}$ value at which the effective cross-sectional area of a section is equal to its gross area (i.e., $A_{\mathrm{e}}=A_{\mathrm{g}}$ ) is denoted by the symbol $L_{c}^{*}$. The graphs presented in Figure 1 also include the values of the effective heights computed using EC3.

The allowance provided in Clause 5.5.2(9) for section change from Class 4 to Class 3 is not applied while plotting the EC3 curve in Figure 1(a) and is applied in Figure 1(b). Even though $\sigma_{\text {com,Ed }}$ is defined in EC3 as the maximum design compressive stress in the considered part, since the design axial load is not considered as a parameter in the study, $\sigma_{\text {com,Ed }}$ is decided to be computed from the design buckling resistance of the member calculated assuming that the member has a Class 3 section for the considered buckling length and steel grade. As shown in Figure 1(b), the change of the section class from 4 to 3 occurs approximately at a buckling length of $6.3 \mathrm{~m}$. One can see that the "jump" in the EC3 curve occurs almost at the same effective length at which $A_{\mathrm{e}}$ becomes equal to $A_{\mathrm{g}}$ according to AISC 360-16. Thus, even though Clause 5.5.1(10) hinders the use of the 
class change defined in Clause 5.5.1(9) when calculating design buckling resistances of compression members, it is believed that the class change can also be used in the calculations of buckling resistances since, when the buckling length exceeds this critical value $\left(L_{c}^{*}\right)$, member buckling occurs before local buckling.

Table 4 lists the smallest buckling lengths $\left(L_{c}^{*}\right)$ and the corresponding member slendernesses $\left(L_{c}^{*} / i\right)$ at which the sections classified as slender-element sections according to AISC $360-16$ or as Class 4 sections according to EC 3 can be treated as nonslender-element or non-Class 4 sections, respectively. As shown in Table 4, for each studied section group, $L_{c}^{*}$ values calculated using AISC 360-16 and EC3 are almost identical when the number of the section is the largest in the group. The difference between $L_{c}^{*}$ values increases slightly as the number of sections decreases. As an example, for S355 steel grade, the values of $L_{c}^{*}$ computed for HEA600 section are equal to $2.71 \mathrm{~m}$ for AISC $360-16$ and $3.25 \mathrm{~m}$ for EC3 whereas those for HEA1000 section are $6.52 \mathrm{~m}$ and $6.36 \mathrm{~m}$, respectively. It is also observed that the $L_{c}^{*}$ (and so $\left.L_{c}^{*} / i\right)$ values for AISC 360-16 are in general smaller than those for EC3 when sections have a slender/Class 4 web and larger when sections have slender/Class 4 flanges.

As far as the design of compression members is concerned, another difference between two specifications is that EC3 requires the verification of both cross section and buckling resistances whereas AISC 360-16 does not separate cross section strength from member strength. In fact, yielding is not a limit state that AISC 360-16 takes into consideration in the design of compression members. According to the design principles defined in AISC 360-16, a uniaxially compressed member can reach its yield load $\left(P_{\mathrm{y}}=F_{\mathrm{y}} A_{\mathrm{g}}\right)$ only when it is fully restrained against any type of buckling, i.e., when $L_{\mathrm{c}} \longrightarrow 0$ and the section does not have any slender element. On the other hand, EC3 allows the use of cross section resistance when the nondimensional slenderness of the member is sufficiently small $(\bar{\lambda} \leq 20)$ or the design value of the applied compression load is sufficiently small. In this study, design resistances are calculated independent of the applied load, so the second allowance is not used, but the first allowance is applied at appropriate buckling lengths.

The buckling curves defined in AISC 360-16 and EC3 also differ to a certain extent. A single buckling curve is defined in AISC 360-16 for all rolled I-shaped members independent of their geometrical and material properties while EC3 defines five different buckling curves depending on the depth to width ratio of the section, flange thickness, steel grade, and buckling axis. As mentioned earlier, the effective lengths of the members for all applicable buckling modes (i.e., flexural buckling about strong axis, flexural buckling about weak axis, and torsional buckling) are assumed to be identical in this study. Hence, when computing the design buckling resistances, for a single shape, it is sufficient to select a single buckling curve which corresponds to the flexural buckling mode about weak axis. As it will be explained later in more detail, for all steel sections and grades considered in the study, only three buckling curves, $a$, $b$, and $c$, are used in the calculation of design buckling resistances.
TABle 4: The smallest buckling lengths $\left(L_{\mathrm{c}}^{*}\right)$ and member slendernesses $\left(L_{c}^{*} / i\right)$ at which the effective cross section of a slenderelement/Class 4 section is equal to its gross area (i.e., $A_{\mathrm{e}}=A_{\mathrm{g}}$ ). The values listed for EC3 are computed applying the class change allowed in Clause 5.5.1(9) in EC3.

\begin{tabular}{|c|c|c|c|c|c|}
\hline \multirow{2}{*}{ Section } & \multirow{2}{*}{ Steel grade } & \multicolumn{2}{|c|}{ AISC $360-16$} & \multicolumn{2}{|c|}{ EC3 } \\
\hline & & $L_{\mathrm{c}}^{*}(\mathrm{~m})$ & $L_{\mathrm{c}}^{*} / i$ & $L_{\mathrm{c}}^{*}(\mathrm{~m})$ & $L_{\mathrm{c}}^{*} / i$ \\
\hline IPE300 & \multirow{8}{*}{ S355 } & - & - & 0.849 & 25.3 \\
\hline IPE330 & & 0.848 & 23.9 & 1.29 & 36.4 \\
\hline IPE360 & & 1.44 & 37.9 & 1.73 & 45.7 \\
\hline IPE400 & & 1.87 & 47.4 & 2.09 & 52.9 \\
\hline IPE450 & & 2.43 & 58.9 & 2.55 & 61.8 \\
\hline IPE500 & & 2.87 & 66.5 & 2.92 & 67.8 \\
\hline IPE550 & & 3.03 & 68.2 & 3.08 & 69.2 \\
\hline IPE600 & & 3.33 & 71.4 & 3.34 & 71.7 \\
\hline HEA550 & \multirow{7}{*}{ S355 } & - & - & 1.83 & 25.6 \\
\hline HEA600 & & 2.71 & 38.4 & 3.25 & 46.1 \\
\hline HEA650 & & 3.80 & 54.6 & 4.07 & 58.4 \\
\hline HEA700 & & 4.00 & 58.0 & 4.18 & 61.1 \\
\hline HEA800 & & 5.30 & 79.8 & 5.23 & 78.7 \\
\hline HEA900 & & 5.88 & 90.5 & 5.73 & 88.2 \\
\hline HEA1000 & & 6.52 & 103 & 6.36 & 100 \\
\hline HEB700 & \multirow{4}{*}{ S355 } & - & - & 1.10 & 16.1 \\
\hline HEB800 & & 3.18 & 47.6 & 3.54 & 53.0 \\
\hline HEB900 & & 4.30 & 65.8 & 4.39 & 67.2 \\
\hline HEB1000 & & 5.26 & 82.5 & 5.17 & 81.0 \\
\hline HEM900 & \multirow{2}{*}{ S355 } & 2.05 & 31.0 & 2.70 & 40.9 \\
\hline HEM1000 & & 4.15 & 64.4 & 4.26 & 66.1 \\
\hline HD260 ×54.1 & \multirow{2}{*}{ S460 } & 3.63 & 57.0 & 2.91 & 45.8 \\
\hline HD $340 \times 74.2$ & & 4.08 & 56.4 & 3.32 & 45.9 \\
\hline
\end{tabular}

Keeping in mind that the buckling curves defined in EC3 plots the variation of (resistance) reduction factor $\chi$ with nondimensional slenderness $\bar{\lambda}$ and realizing that the $F_{\mathrm{cr}} / F_{\mathrm{y}}$ ratio computed using AISC $360-16$ can also be considered as a kind of (strength) reduction factor, it can be valuable to plot the variation of $F_{\underline{\mathrm{c}}} / F_{\mathrm{y}}$ (which is called "nondimensional critical stress") with $\bar{\lambda}$ and compare it with the buckling curves defined in EC3. To plot the so-called "buckling curve for AISC 360-16," member slenderness $\left(L_{\mathrm{c}} / i\right)$ appearing in equation (4) should be converted to nondimensional slenderness $\bar{\lambda}$. For this conversion, the following relation can be used:

$$
\bar{\lambda}=\frac{1}{\pi} \sqrt{\frac{F_{\mathrm{y}}}{E}}\left(\frac{L_{\mathrm{c}}}{i}\right) .
$$

As defined in AISC $360-16, E=200 \mathrm{GPa}$ should be used in equation (17). It is to be noted that equation (17) is valid only for non-Class 4 sections. For members with Class 4 sections, the value of $\bar{\lambda}$ calculated using equation (17) should be reduced by multiplying it with the square root of the ratio of the effective area of the cross section to its gross area $\left(A_{\mathrm{e}} /\right.$ $A_{\mathrm{g}}$ ). From Table 3, for the studied shapes and steel grades, the maximum value of this reduction factor can be computed for HEA1000 section and S355 steel grade as 6.2\%. Accordingly, the buckling curve plotted for AISC 360-16 using equation (17) can be accepted to be approximately valid for all studied sections. 
Figure 2 shows the three buckling curves defined in EC3 and used in the study, $a, b$, and $c$, as well as the buckling curve for AISC 360-16 (named as "AISC 360-16, nominal" in the plot). The plot of $F_{\mathrm{cr}} / F_{\mathrm{y}}$ with $\bar{\lambda}$ can be considered as a kind of a "nominal" buckling curve since while calculating the design compressive strength, AISC 360-16 requires the reduction of the nominal strength $10 \%$. For this reason, the "design" buckling curve for AISC 360-16 (named as "AISC $360-16$, design" in the plot) is also added to Figure 2 by plotting the variation of $\phi_{\mathrm{c}} F_{\mathrm{cr}} / F_{\mathrm{y}}$ (called "nondimensional critical design stress") with $\bar{\lambda}$.

When the nominal buckling curve for AISC 360-16 in Figure 2 is compared with the buckling curves defined in EC3, it is seen that the former remains below curve $a$ when $\bar{\lambda}$ is between 1.05 and 1.85 , below curve $b$ when $\bar{\lambda}$ is between approximately 0.35 and 2.55, and below curve $c$ when $\bar{\lambda}$ is smaller than 0.25 . For the other values of $\bar{\lambda}$, the nominal buckling curve for AISC 360-16 lays over the mentioned EC3 buckling curves. When comparing the design strengths with design resistances, it seems to be more rational to use the "design" buckling curve plotted for AISC 306-16. Since this curve is obtained by multiplying the ordinates of the "nominal" buckling curve with $\phi_{c}=0.90$, it remains below curve $a$ for all studied values of $\bar{\lambda}$. This can also be seen from Figure 3, which plots the ratio of reduction factor $(\chi)$ to nondimensional critical design stress $\left(\phi_{\mathrm{c}} F_{\mathrm{cr}} / F_{\mathrm{y}}\right)$, which is named in this study as "capacity reduction ratio." The capacity reduction ratio is smaller than unity, which means that the design buckling curve of AISC 360-16 lays above the specified buckling curve of EC 3 , when $1.0 \leq \bar{\lambda} \leq 1.6$ for curve $b$ and when $0.7 \leq \bar{\lambda} \leq 2.0$ for curve $c$, approximately. Figure 3 also shows that unless nondimensional slenderness exceeds 3.0 , the capacity reduction ratios do not exceed 1.18. For the studied EC 3 curves, the smallest value of the capacity reduction ratios, 0.877 , occurs for curve $c$ when $\bar{\lambda}=1.25$ approximately.

Buckling curves can also be plotted as a function of member slenderness $\left(L_{\mathrm{c}} / i\right)$. In this case, it is realized that the curves depend on the yield strength of steel $\left(F_{\mathrm{y}}\right)$. Such curves are plotted in Figure 4 for two different values of $F_{\mathrm{y}}: 235$ and $440 \mathrm{MPa}$. As shown in the figure, for a compression member with a specified member slenderness, the reduction factors computed using both specifications decrease, in general, as $F_{\mathrm{y}}$ increases.

To investigate the dependence of buckling curves plotted as a function of member slenderness to $F_{y}$, the capacity reduction ratios are plotted in Figure 5 for four different values of yield strengths: $235,275,355$, and $440 \mathrm{MPa}$. It is seen that the minimum value of the capacity reduction ratios plotted for each EC 3 curve $(a, b$, or $c)$ remains constant whereas the member slenderness at which this minimum value occurs decreases with increasing yield strength. As an example, the minimum value of the capacity ratios computed by dividing $\chi$ values for buckling curve $b$ defined in EC3 to $\left(\phi_{\mathrm{c}} F_{\mathrm{cr}} / F_{\mathrm{y}}\right)$ values is equal to 0.961 for all studied yield strengths; on the other hand, this value is achieved when $L_{\mathrm{c}} / i$ is approximately equal to 125 for $F_{\mathrm{y}}=235 \mathrm{MPa}, 115$ for $F_{\mathrm{y}}=275 \mathrm{MPa}, 100$ for $F_{\mathrm{y}}=355 \mathrm{MPa}$, and 90 for $F_{\mathrm{y}}=440 \mathrm{MPa}$.

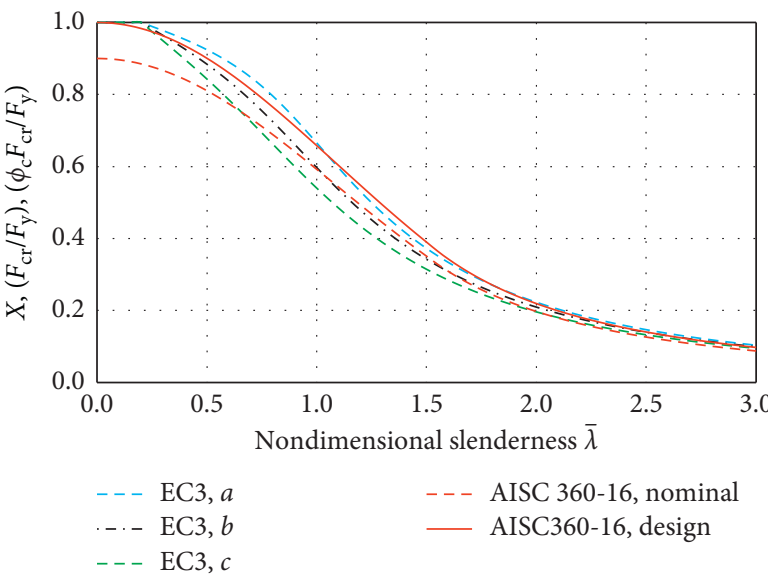

Figure 2: Comparison of the nominal and design buckling curves for AISC 360-16 (denoted as "AISC 360-16, nominal" and "AISC 360-16, design" in the graph) with three buckling curves $a, b$, and $c$ defined in EC3 (denoted as "EC3, a," "EC3, b," and "EC3, c" in the graph).

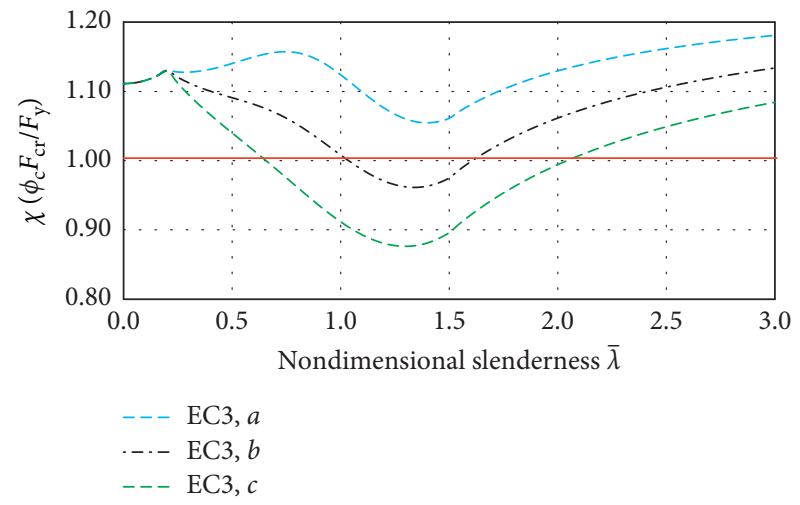

FIgURe 3: Capacity reduction ratios $\left(\chi /\left(\phi_{\mathrm{c}} F_{\mathrm{cr}} / F_{\mathrm{y}}\right)\right)$ for three EC3 buckling curves $a, b$, and $c$.

Figure 5 also shows that the value of the capacity reduction ratio for a specific value of $L_{\mathrm{c}} / i$ also depends on $F_{\mathrm{y}}$. For example, for $L_{\mathrm{c}} / i=60$ and curve $b$, the capacity reduction ratio is 1.08 for $F_{\mathrm{y}}=235 \mathrm{MPa}, 1.07$ for $F_{\mathrm{y}}=275 \mathrm{MPa}, 1.05$ for $F_{\mathrm{y}}=355 \mathrm{MPa}$, and 1.03 for $F_{\mathrm{y}}=440 \mathrm{MPa}$. In other words, the ratio decreases as $F_{\mathrm{y}}$ increases for this particular case. However, this conclusion cannot be generalized to all $L_{\mathrm{c}} / i$ values since the corresponding values are equal to $0.98,1.01,1.05$, and 1.07 when $L_{\mathrm{c}} / i=140$ for the same yield strengths and the buckling curve; that is, the capacity reduction ratio increases in this case as $F_{\mathrm{y}}$ increases. Nevertheless, the effect of yield strength on capacity reduction ratio is limited (not to exceed about $10 \%$ ). For the studied steel grades and member slendernesses, the minimum and maximum values of the capacity reduction ratio are found to be 0.876 (for buckling curve $c$ ) and 1.18 (for buckling curve $a$ and $F_{\mathrm{y}}=440 \mathrm{MPa}$ ), respectively.

3.2. Comparison of Design Compressive Strengths and Design Buckling Resistances. Using the design principles summarized in the previous sections, the design compressive 


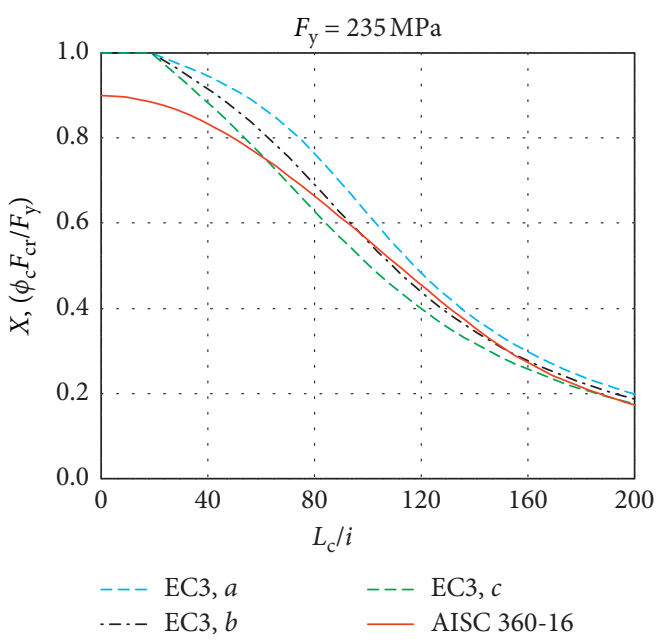

(a)

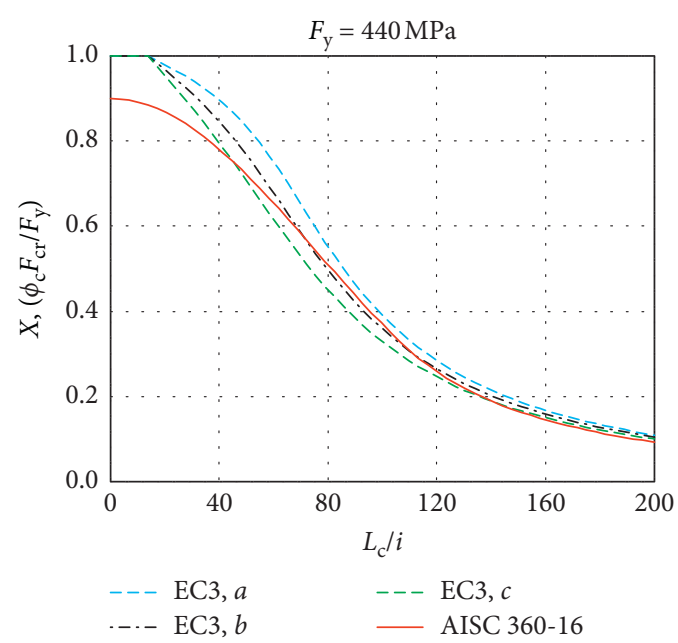

(b)

Figure 4: Buckling curves plotted as a function of member slenderness $\left(L_{\mathrm{c}} / i\right)$ for two different $F_{\mathrm{y}}$ values $(235$ and $440 \mathrm{MPa})$.

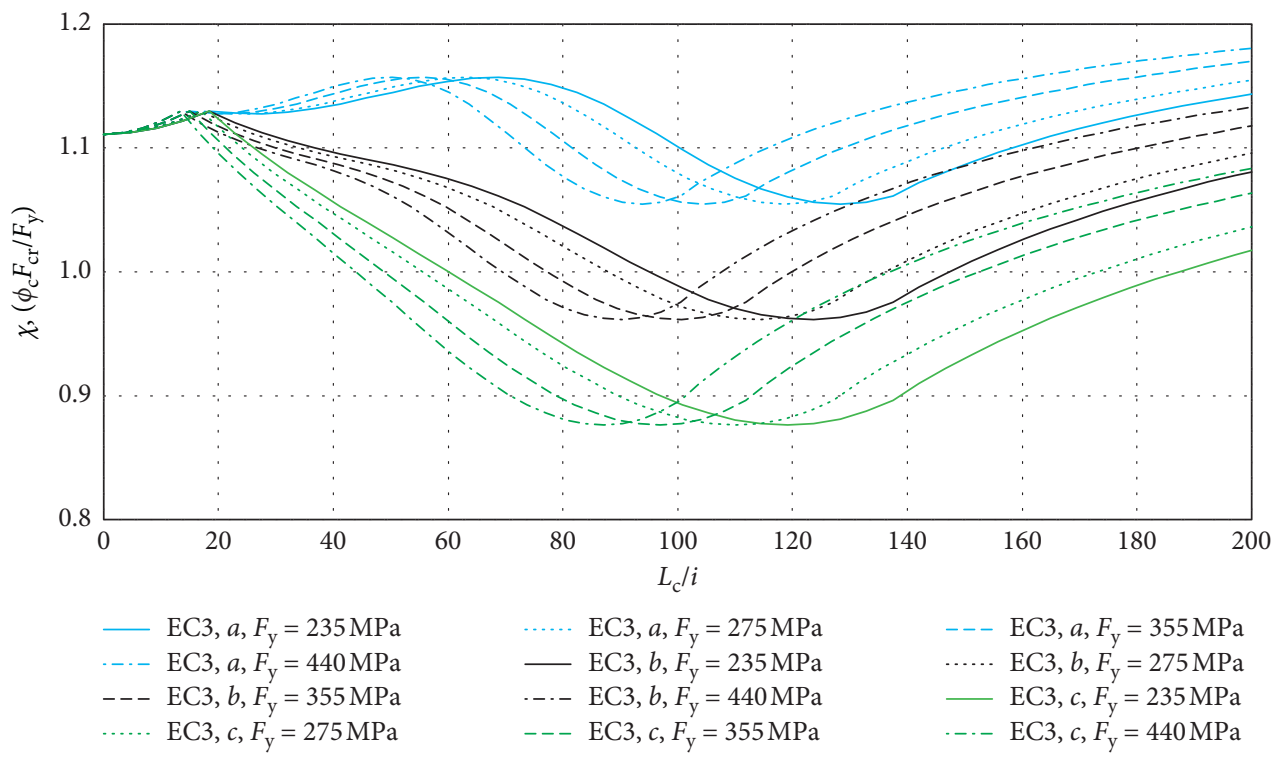

Figure 5: The effect of yield strength $\left(F_{\mathrm{y}}\right)$ on capacity reduction ratio $\left(\chi /\left(\phi_{\mathrm{c}} F_{\mathrm{cr}} / F_{\mathrm{y}}\right)\right)$ plotted as a function of member slenderness $\left(L_{\mathrm{c}} / i\right)$. The blue (top), black (intermediate), and green (bottom) curves are plotted for buckling curves $a, b$, and $c$, respectively.

strengths $\left(\phi_{\mathrm{c}} P_{\mathrm{n}}\right)$ and design buckling resistances $\left(N_{\mathrm{b}, \mathrm{Rd}}\right)$ are calculated for all sections and steel grades examined in the scope of the study and for different values of effective lengths. For simplicity, the generic term "capacity" is used in the study to express design compressive strength if the design is based on AISC 360-16 and design buckling resistance if the design is based on EC3. Figures 6(b), 6(d), 6(f), and $6(\mathrm{~h})$ plot the capacities calculated using two specifications for typical members with different sections and steel grades. It is to be noted that effective cross-sectional areas are used in capacity calculations if the member has a slenderelement/Class 4 section and if $L_{\mathrm{c}}<L_{\mathrm{c}}^{*}$. In other words, while calculating the design buckling resistances, Clause 5.5.1(9) in EC3 is taken into consideration. Since a user note in Section E2 of AISC 360-16 recommends and Section 8.1.1 in SDCSS requires that the effective slenderness ratio not exceed 200, the design compressive strengths are calculated only for member lengths not exceeding $200 i_{\min }$, where $i_{\min }$, is the radius of gyration about weak axis, whereas the design resistances are computed up to $L_{c}=15 \mathrm{~m}$ without any limitation on member slenderness.

From the capacity curves presented in Figure 6, it can be seen that the design strengths are in general smaller than the design resistances when buckling lengths are small. As the length of the member increases, the difference between the capacities reduces and either the capacities become almost equal or the design strengths exceed the design resistances. At larger buckling lengths, the strength curves fall below the resistance curves again. Despite plotted for the same steel grade, the capacity curves given in Figure 6 for members 

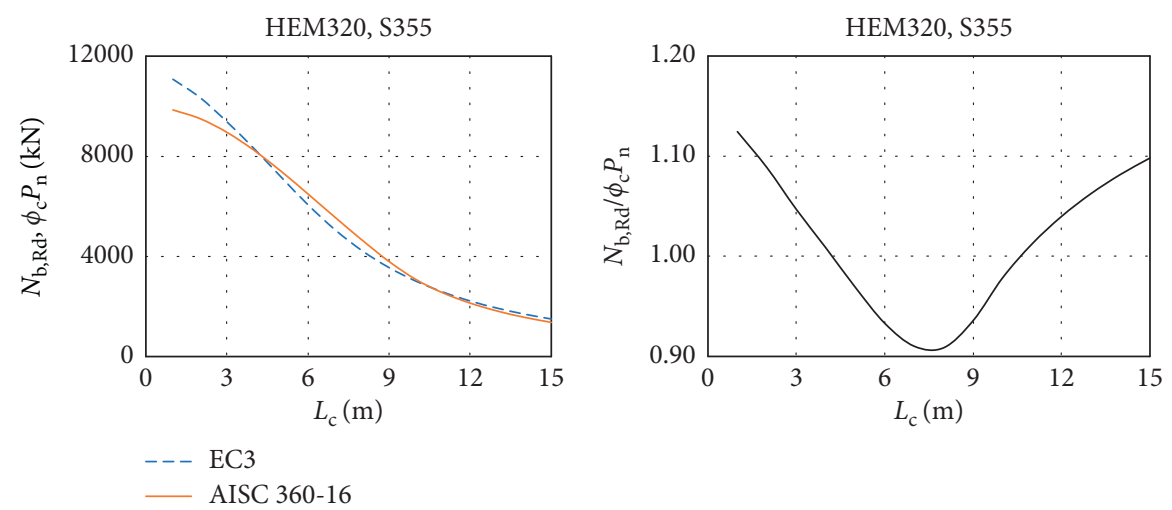

(a)

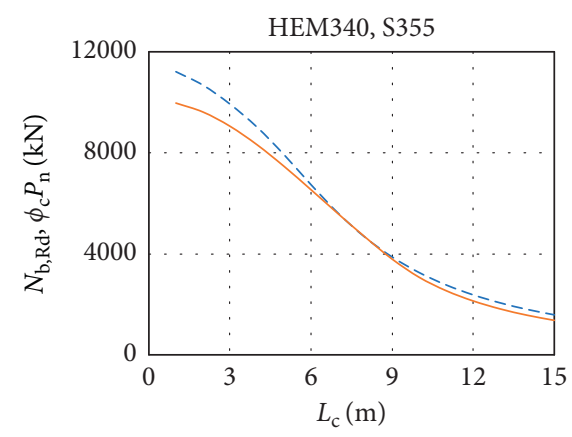

(b)

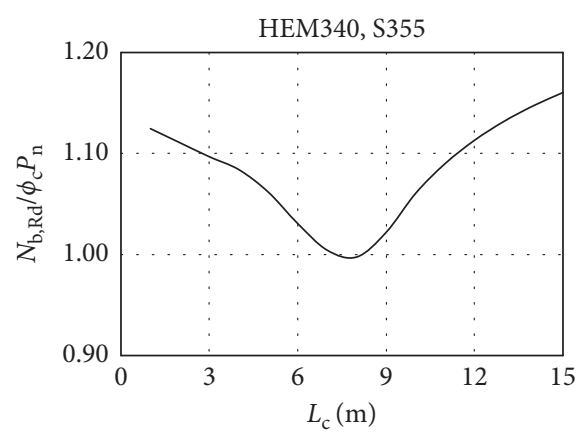

- - EC3

— AISC 360-16

(c)

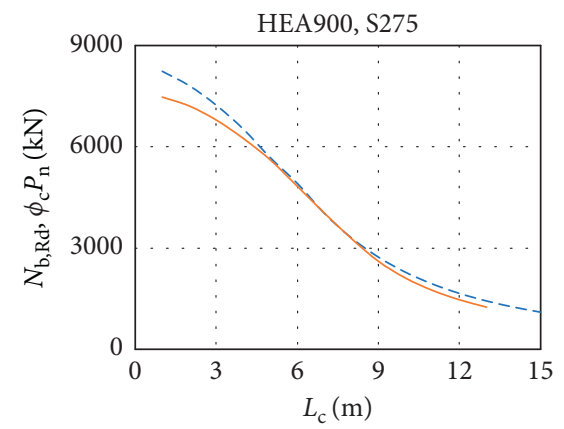

(d)

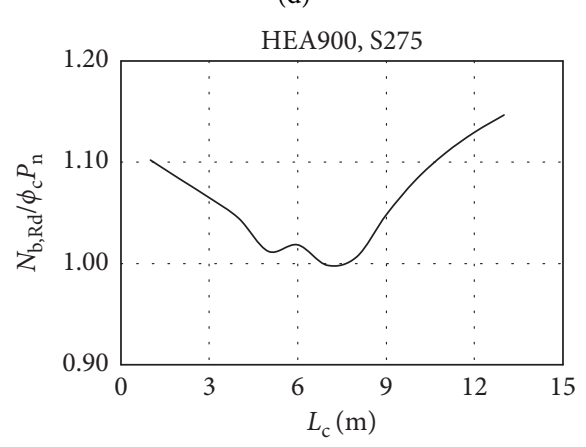

-.- EC3

— AISC 360-16

(e)

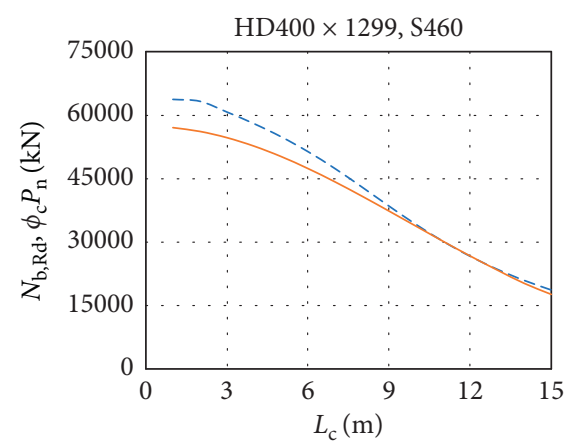

(f)

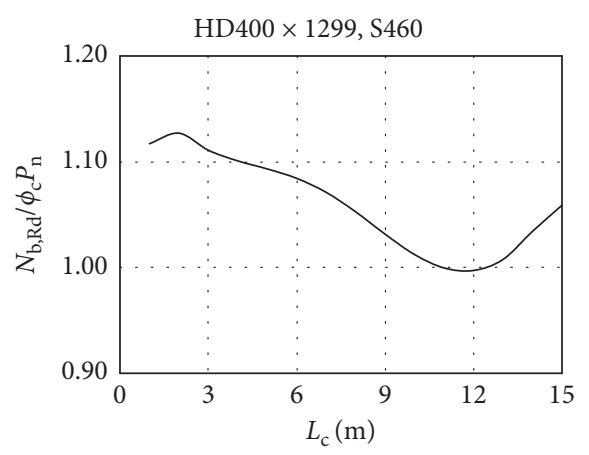

- - - EC3

— AISC 360-16

(g)

(h)

FIgURE 6: Variation of design compression capacities (design compressive strengths $\left(\phi_{\mathrm{c}} P_{\mathrm{n}}\right)$ for AISC 360 -16 and design buckling resistances $\left(N_{\mathrm{b}, \mathrm{Rd}}\right)$ for EC3) with effective member length $\left(L_{\mathrm{c}}\right)$ for some studied shapes and steel grades. The graphs in (a, c, e, g) compare the capacities, and the graphs in $(\mathrm{b}, \mathrm{d}, \mathrm{f}, \mathrm{h})$ plot the capacity ratios $\left(N_{\mathrm{b}, \mathrm{Rd}} / \phi_{\mathrm{c}} P_{\mathrm{n}}\right)$. 
with HEM 320 and HEM 340 sections, which have successive numbers among the studied HEM sections and have quite similar geometrical properties, are rather different. Table 2 reveals that both sections are classified as nonslender-element/non-Class 4 sections for the investigated steel grade (S355). The difference between the capacity curves is indeed caused by the fact that while the $d / b$ ratio for HEM 320 is 1.16, that for HEM 340 is 1.22 , which means that the appropriate buckling curve to be used in the calculation of design buckling resistances changes from $c$ to $b$ when the section number increases from 320 to 340 . In fact, among all HEM sections examined in the study, the sections with numbers smaller than 340 have $d / b$ ratios smaller than 1.2 whereas the sections with greater numbers have $d / b$ ratios larger than 1.2. Thus, the buckling curve $c$ must be used in resistance calculations for HEM sections with numbers not exceeding 320 whereas curve $b$ must be used for greater HEM sections. In fact, similar changes in appropriate buckling curves occur for the studied HEA and HEB sections. Since the $d / b$ ratios of HEA and HEB sections with numbers equal to 400 or greater are larger than 1.2, the buckling curve $b$ must be used in their resistance calculations. For smaller HEA and HEB sections, the buckling curve changes to $c$. It is worth noting that since all I-sections examined in the study have $d / b$ ratios larger than 1.2 , the buckling curve $b$ is used in their resistance calculations. It should be recalled that none of the studied I and HE sections have flanges with a thickness larger than $40 \mathrm{~mm}$. As far as the studied HD sections are concerned, the flange thickness is another parameter in the selection of appropriate buckling curve since $19 \mathrm{HD}$ sections have $t_{\mathrm{f}}>40 \mathrm{~mm}$. Surprisingly, it is found that the design buckling resistances of all HD profiles can be calculated using a single buckling curve, curve $c$, provided that the steel grade is S275 or S355. In the case of S460 steel grade, the buckling curve $a$ should be used for the HD sections with $t_{\mathrm{f}} \leq 100 \mathrm{~mm}$ and the buckling curve $b$ should be used for the HD sections with thicker flanges.

As shown in Figure 6, since the buckling curve $c$ is used in the calculation of the design resistances of the member with HEM 320 section, the design strengths exceed the design resistances at moderate buckling lengths.

However, it is rather difficult to compare the safety levels of both specifications from the capacity curves. For easier comparison, the capacity ratio curves, i.e., the variation of the ratios of design buckling resistances to design compressive strengths $\left(N_{\mathrm{b}, \mathrm{Rd}} / \phi_{\mathrm{c}} P_{\mathrm{n}}\right)$ with buckling lengths, are also plotted and given in Figures 6(b), 6(d), 6(f), and 6(h). A capacity ratio exceeding unity means that AISC $360-16$ gives safer capacities than EC3. Among the capacity ratio curves plotted in Figure 6, only the curve plotted for the member with HEM 320 section and S355 steel grade has values smaller than 1.0, since only for this member the buckling curve $c$ is used while calculating design buckling resistances. For the other three members, the buckling curve $b$ is used. The comparison of the capacity ratio curves for HEM 320 and HEM 340 indicates that the shape of the curves is similar; the capacity ratio is larger than 1.0 when $L_{c}=1 \mathrm{~m}$, then decreases towards a minimum as $L_{c}$ increases, and finally increases with increasing $L_{\mathrm{c}}$. The capacity ratio curve plotted for the member with HEA900 section and S275 steel grade also has a similar shape; but, a sudden "jump" occurs at about $L_{\mathrm{c}}=5 \mathrm{~m}$. It can be seen from Table 2 that HEA900 is a slender-element section according to AISC 360-16 and Class 4 section according to EC3 for all studied steel grades. It is found that the gross cross-sectional area can be used in its capacity calculations when $L_{\mathrm{c}}>5.17 \mathrm{~m}$ if AISC $360-16$ is used in the design and when $L_{\mathrm{c}}>5.11 \mathrm{~m}$ if EC3 is used with the allowance given in Clause 5.5.1(9). Since the transition from the use of effective area to gross area is abrupt in EC3, a local peak occurs in the capacity ratio curve plotted for HEA900 member when class change occurs, i.e., when $L_{c}$ is equal to $5.17 \mathrm{~m}$. As it will be shown later, these local peaks are apparent in capacity ratio curves of all members with Class 4 sections.

The capacity ratio curve presented in Figure 6 for the member with HD $400 \times 1299$ section and S460 steel grade is different from the others in the same figure in that it has a peak at small buckling lengths. In fact, the capacity ratio curve plotted for this member resembles the capacity reduction ratio curves given in Figure 5. The reason for the increase of the capacity ratio with increasing buckling lengths at fairly small buckling lengths is the fact that EC3 allows ignoring the buckling effects if the value of the nondimensional slenderness is smaller than 0.2 whereas AISC 360-16 does not have such an allowance. In fact, similar peaks also exist in the other capacity curves presented in Figure 6; however, since the corresponding $L_{\mathrm{c}}$ values are smaller than $1 \mathrm{~m}$, which is the minimum length considered while plotting the capacity ratio curves, they are not seen in the presented plots. It is worth noting that HD $400 \times 1299$ section is the largest section considered in the study and it has a flange thickness larger than $100 \mathrm{~mm}$. For this reason, while calculating its design resistance, the buckling curve $b$ is used. It can also be noticed that the "moderate" buckling lengths at which the capacity ratio attains its minimum value are relatively large (about $12 \mathrm{~m}$ ) for this section. Nevertheless, similar to the members with HEM 340 and HEA 900 sections, the value of the capacity ratios computed for HD $400 \times 1299$ member (S460) does not fall below 1.0 for nearly all studied buckling lengths, meaning that the design compressive strengths are almost always smaller than the design buckling resistances.

This seems to be contradicting the capacity reduction ratio curves given in Figures 3 and 4, where the curves plotted for the buckling curve $b$ have a minimum value of 0.961. Indeed, this difference occurs due to the fact that both specifications use different values for the modulus of elasticity. It can be realized that while drawing the capacity reduction ratio curves, the conversion between nondimensional slenderness $(\bar{\lambda})$ and member slenderness $\left(L_{\mathrm{c}} / i\right)$ is done using equation (17), where $E=200 \mathrm{GPa}$ is taken as defined in AISC 360-16. Figure 7 shows the effect of modulus of elasticity on capacity ratio curves plotted for different values of member slenderness.

In Figure 7, the design resistances of the member with IPE 450 section and S355 steel grade are computed both using $E=210 \mathrm{GPa}$ (as defined in EC3) and using $E=200 \mathrm{GPa}$ (as defined in AISC 360-16). The design strengths are 


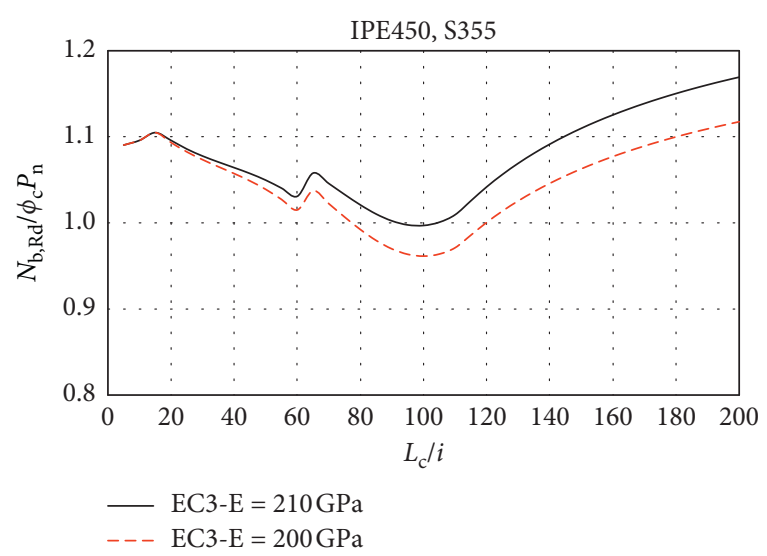

FIgURE 7: The effect of different values of elasticity modulus on the capacity ratio curve plotted for a member with IPE450 section and S355 steel grade. The black and solid curve presents the capacity curve with design resistances calculated using $E_{\mathrm{c}}=210 \mathrm{GPa}$ whereas the red and dashed curve presents that calculated using $E_{\mathrm{c}}=200 \mathrm{GPa}$.

computed using only $E=200 \mathrm{GPa}$. As shown in Figure 7, when capacities are calculated using the same value of elasticity, the minimum capacity ratio decreases from approximately $1.0(0.997)$ to 0.961 . Thus, it can be concluded that even though the capacity reduction ratio curves given in Figures 3 and 4 are more general, the capacity ratio curves given in Figure 6 are more realistic. It is also worth noting that since IPE450 section is a slender-element/Class 4 section for S355 steel grades, a sudden jump occurs when it is allowed to be treated as a nonslender-element/non-Class 4 section.

In an attempt to generalize the results, the capacity ratio curves are plotted for all sections and steel grades examined in the study and presented in Figures 8-13. In the figures, the variations of the capacity ratios with member length (on the top plots) as well as with member slenderness (on the bottom plots) are presented. The capacity ratio versus length curves are plotted for buckling lengths starting from $L=1.0 \mathrm{~m}$ to the length allowed by AISC $360-16\left(200 i_{\min }\right)$ at an interval of 1.0 meters. On the other hand, the capacity ratio versus slenderness curves are plotted for the slenderness ratios starting from 5 to 200 with an interval of 5 .

It is to be noted that as the number of a section increases in a particular section group, its capacity ratio-length curve "moves towards the right." In other words, the buckling length at which the capacity ratio takes its minimum value increases as the number of the section increases. This occurs due to the fact that for a specified steel grade and section group, different capacity ratio-length curves reduce to a single capacity ratio-slenderness curve provided that the same buckling curve is used in resistance calculations and that the member has a nonslender-element and non-Class 4 section. Surely, this single curve takes its minimum value at a single value of member slenderness. However, as the radii of gyration of sections in a particular section group increase in general as their number increases, the buckling length at which the capacity ratio becomes minimum increases with the increase in section number. For example, as shown in Figure 8 , since none of the studied IPN sections have slender/Class 4 element and the design resistances of all studied IPN members are calculated using the buckling curve $b$, a single capacity ratio-slenderness curve is obtained for all IPN members for a specific steel grade.

As far as the studied IPE members are concerned, similar to the IPN members (Figure 8), the capacity ratio-length curves reduce to a single capacity ratio-slenderness curve for members having nonslender-element/non-Class 4 sections (see Figure 9). As shown in Figure 7, the main effect of having a Class 4 section on capacity ratio curve is the appearance of an abrupt increase in capacity ratio when the class change allowed in Clause 5.5.1(9) of EC3 is applied. Surely, after the class change (i.e., when $L_{\mathrm{c}}>L_{\mathrm{c}}^{*}$ ), the capacity ratio-slenderness curve for a member with a Class 4 section coincides with the capacity ratio-slenderness curve plotted for members with non-Class 4 sections. Since the $L_{\mathrm{c}}^{*}$ values for each section with a slender-element/Class 4 element are different, the transition to the "basic" curve occurs in general at different lengths and slendernesses.

The capacity ratio-slenderness curves plotted for HEshaped members differ from those for I-shaped members in that the capacity ratio-length curves plotted for the former reduce to two different capacity ratio-slenderness curves. This occurs due to the fact that two different buckling curves are used while calculating the design resistances of $\mathrm{HE}$ shaped members.

As already mentioned, for members with HEA or HEB sections with numbers smaller than 400 and HEM sections with numbers smaller than 340 , the buckling curve $c$ is used, and for members with greater section numbers, the buckling curve $b$ is used. These two "basic" capacity ratio-slenderness curves can directly be seen from the plot given in Figure 12 for HEM members with S235 steel grade (continuous curves) and since none of the studied HEM sections is classified as slender-element or Class 4 for this steel grade. The top curves in these plots correspond to the large HEM sections, while the bottom curves correspond to the smaller HEM sections. Except HEM members with a steel grade of S235, all studied section groups with HE shapes contain Class 4 sections. However, as given in Table 2, since the numbers of all Class 4 sections are larger than the numbers mentioned above, all "jumps" are observed in the top curves.

The capacity ratio-slenderness curves plotted for $\mathrm{HD}$ members in Figure 13 differ from the curves plotted for the members with other shapes in that there are at least six different curves in the graphs plotted for HD sections. This occurs due to the fact for a specified steel grade, the studied HD sections can have six different yield strengths according to their flange thicknesses as listed in Table 1. Thus, even though a single buckling curve, curve $c$, is used for all studied HD sections with steel grade of S275 or S355, the capacity ratio versus slenderness curves do not reduce to a single curve. Nevertheless, the effect of yield strength is not considerable as shown in the plots. For S460 steel grade, the buckling curve $b$ is used for five heavy HD sections (with $t_{\mathrm{f}}$ exceeding $100 \mathrm{~mm}$ ), none of which has Class 4 elements. Since the yield strength is also constant for these sections, the 


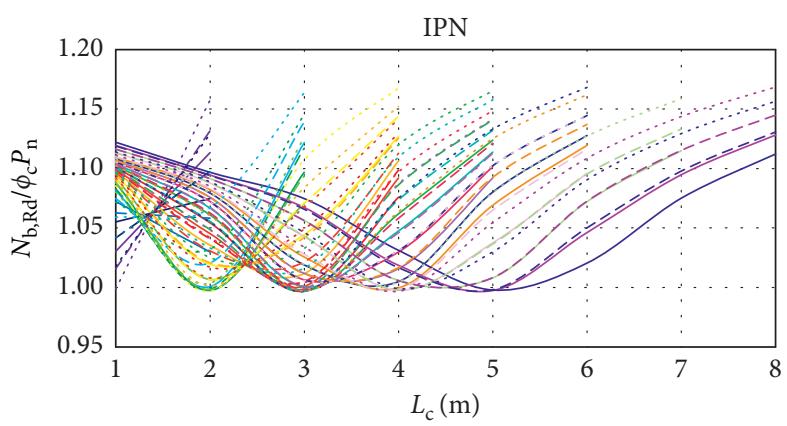

(a)

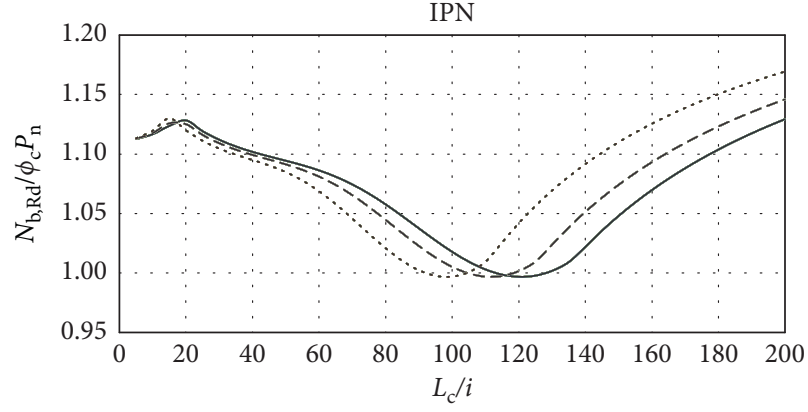

(b)

FIGURE 8: Variation of capacity ratio with buckling length $L_{\mathrm{c}}(\mathrm{a})$ and with member slenderness $L_{\mathrm{c}} / i$ (b) for studied IPN members. In each plot, the solid, dashed, and dotted curves with identical colours represent the capacity curves plotted for a particular section when the steel grades are S235, S275, and S355, respectively.

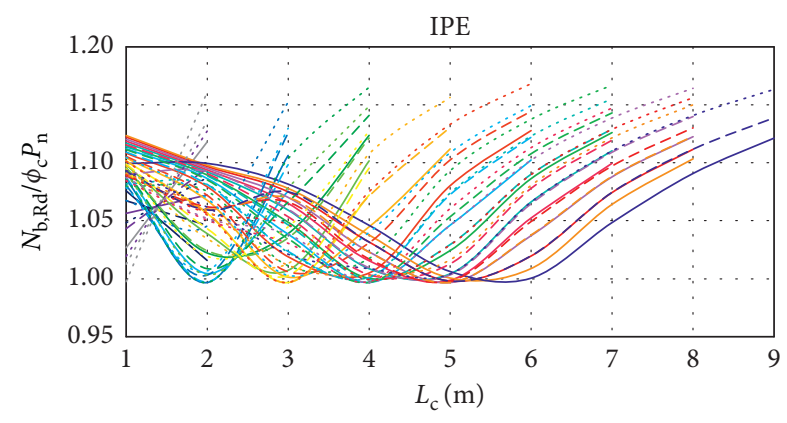

(a)

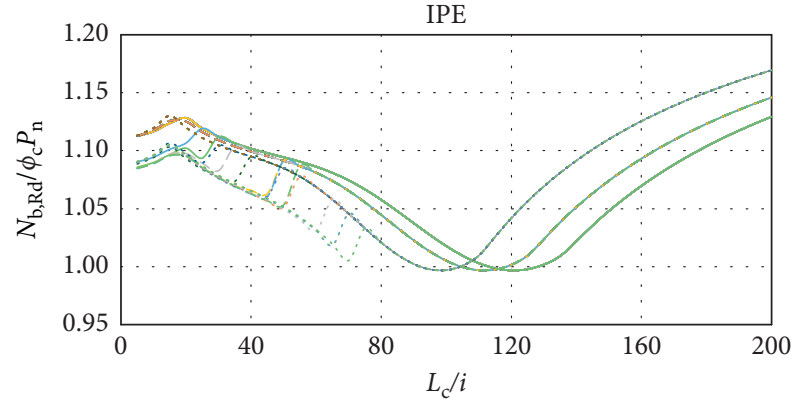

(b)

FIGURE 9: Variation of capacity ratio with buckling length $L_{\mathrm{c}}$ (a) and with member slenderness $L_{\mathrm{c}} / i$ (b) for studied IPE members. In each plot, the solid, dashed, and dotted curves with identical colours represent the capacity curves plotted for a particular section when the steel grades are S235, S275, and S355, respectively.

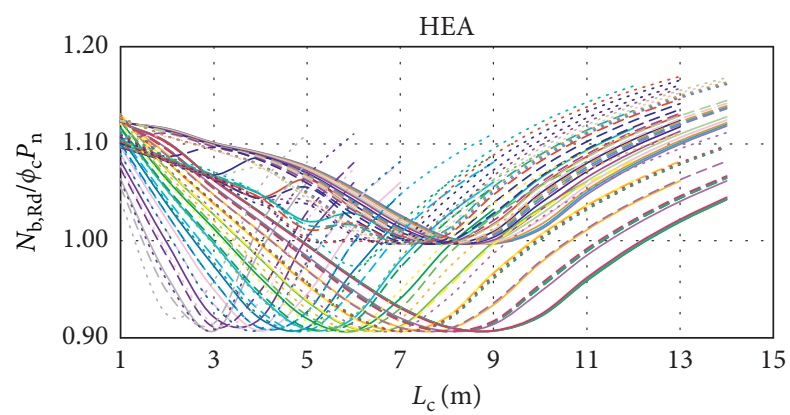

(a)

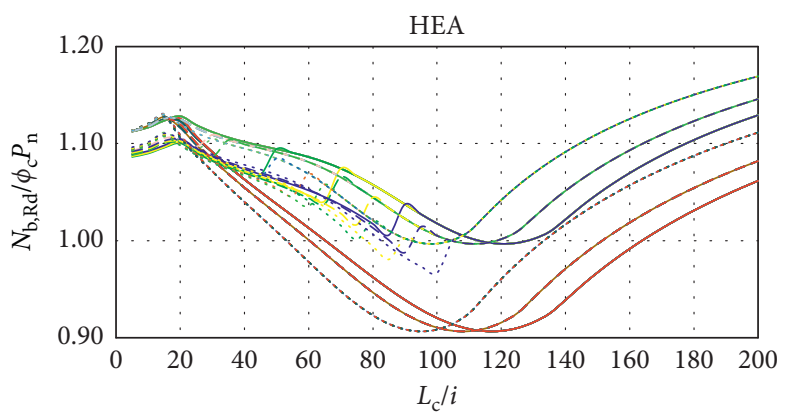

(b)

Figure 10: Variation of capacity ratio with buckling length $L_{\mathrm{c}}$ (a) and with member slenderness $L_{\mathrm{c}} / i$ (b) for studied HEA members. In each plot, the solid, dashed, and dotted curves with identical colours represent the capacity curves plotted for a particular section when the steel grades are S235, S275, and S355, respectively.

capacity ratio-length curves plotted for members with these heavy HD shapes reduce to a single capacity ratio-slenderness curve (see Figure 13(f)). Among all sections and steel grades examined in the study, the buckling curve $a$ is used only in the calculation of the design resistances of the HD members with flange thicknesses smaller than $100 \mathrm{~mm}$. In this case, the minimum value of the capacity ratio is about 1.10. In other words, the design strengths of these HD members are smaller than the design resistances for all studied member slendernesses. Since the flange thicknesses of two HD members with Class 4 sections are smaller than $100 \mathrm{~mm}$, both jumps are observed in the top curves plotted for HD members with S460 steel grade, which also depend on the yield strength slightly.

In general, for members with a nonslender-element and non-Class 4 section, the shapes of the capacity ratio-slenderness 


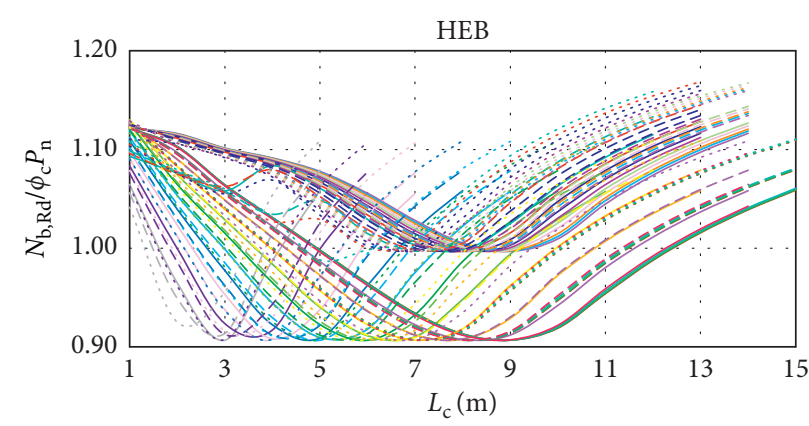

(a)

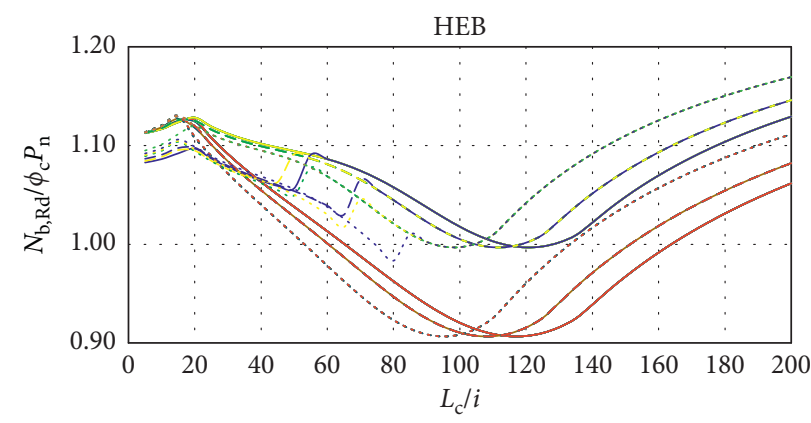

(b)

FIgURe 11: Variation of capacity ratio with buckling length $L_{\mathrm{c}}$ (a) and with member slenderness $L_{\mathrm{c}} / i$ (b) for studied HEB members. In each plot, the solid, dashed, and dotted curves with identical colours represent the capacity curves plotted for a particular section when the steel grades are S235, S275, and S355, respectively.

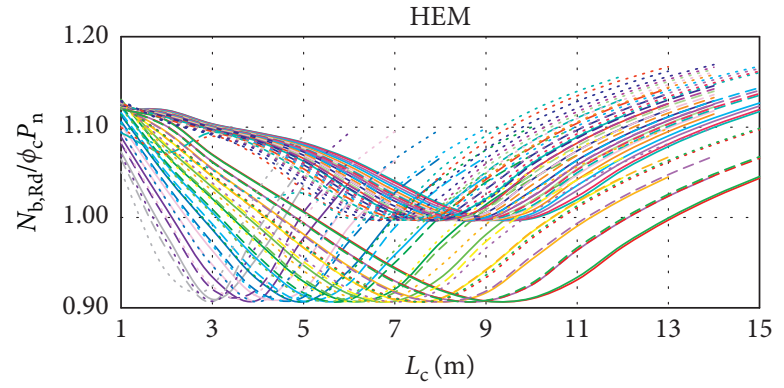

(a)

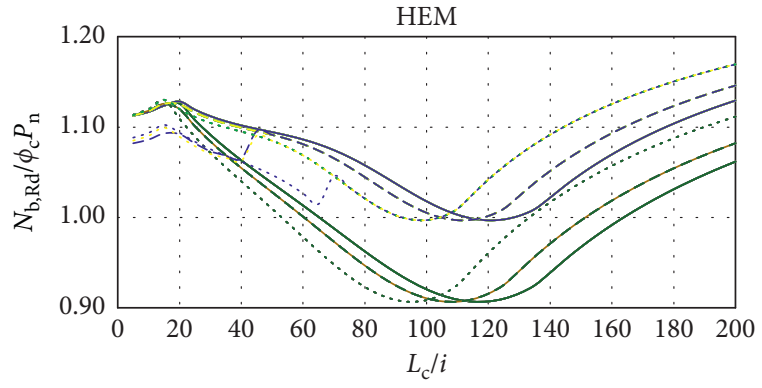

(b)

FIGURE 12: Variation of capacity ratio with buckling length $L_{\mathrm{c}}(\mathrm{a})$ and with member slenderness $L_{\mathrm{c}} / i$ (b) for studied HEM members. In each plot, the solid, dashed, and dotted curves with identical colours represent the capacity curves plotted for a particular section when the steel grades are S235, S275, and S355, respectively.

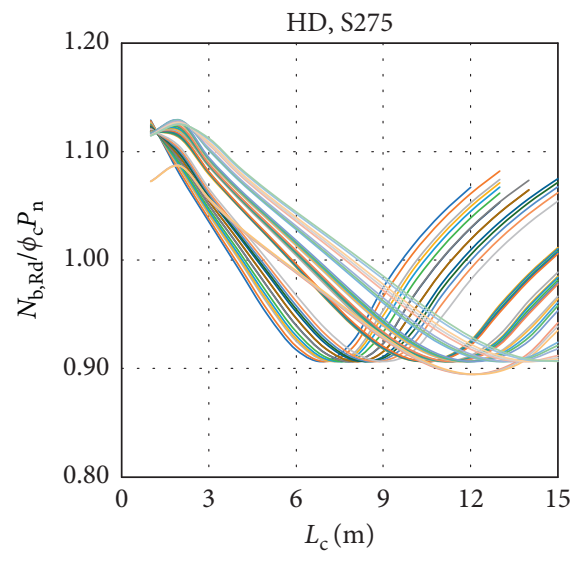

(a)

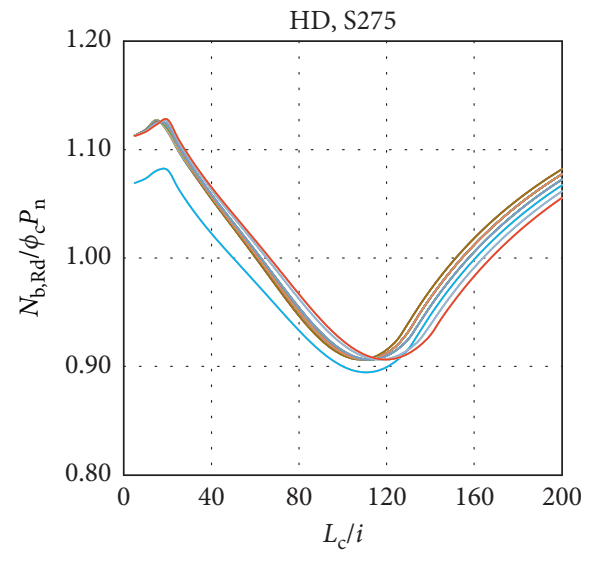

(b)

FIgURe 13: Continued. 


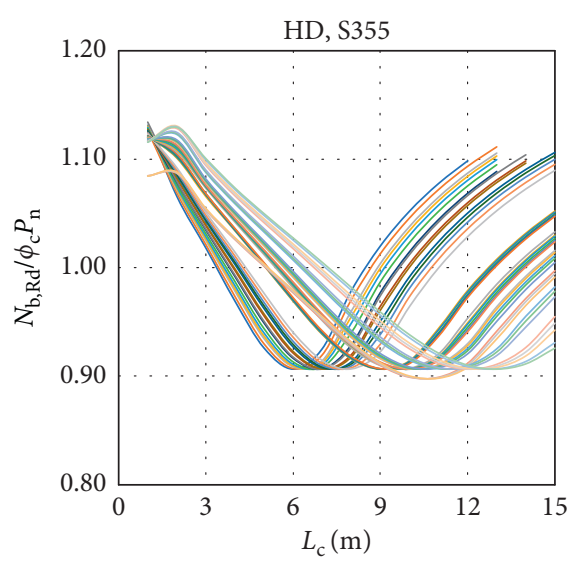

(c)

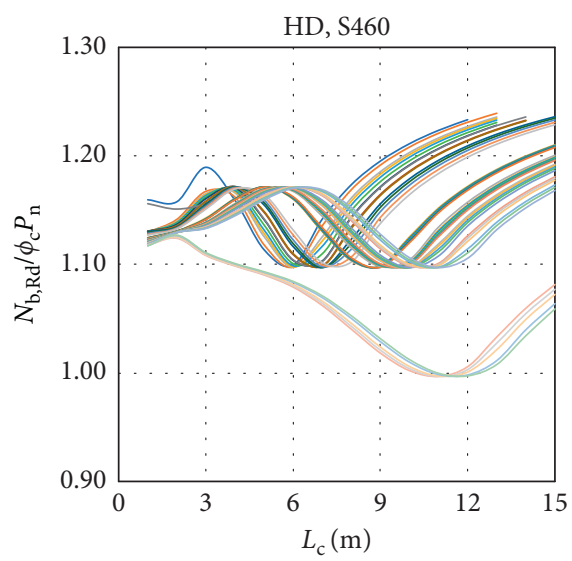

(e)

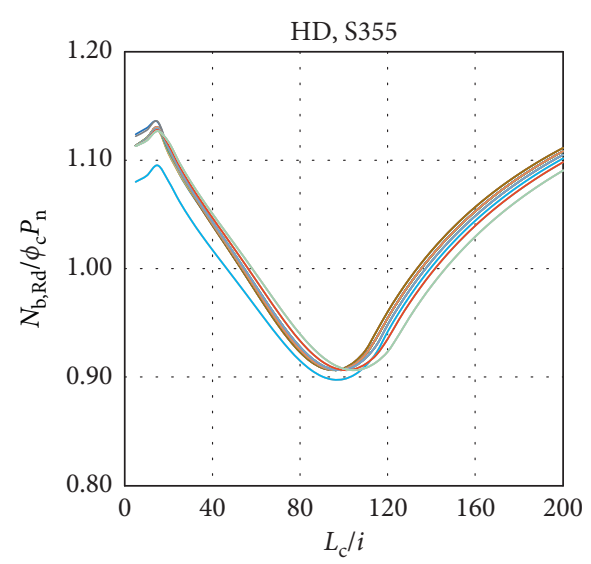

(d)

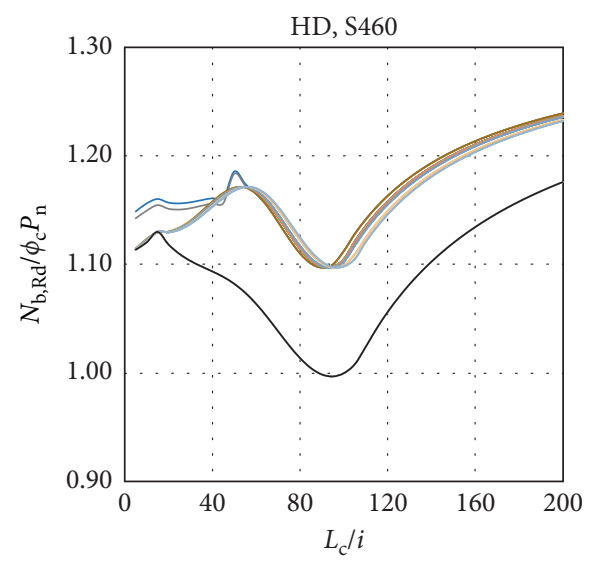

(f)

FIGURE 13: Variation of capacity ratio with buckling length $L_{\mathrm{c}}(\mathrm{a}, \mathrm{c}, \mathrm{e})$ and with member slenderness $L_{\mathrm{c}} / i(\mathrm{~b}, \mathrm{~d}, \mathrm{f})$ for studied HD members.

curves are identical to the shapes of the capacity reduction ratio curves presented in Figure 5. Independent of the section type, section number, and steel grade, the capacity curves start with a value of approximately 1.11. It is known that the nominal capacity of a short compression member with a compact cross section, which does not have any buckling limit state, is equal to its yield load $\left(F_{\mathrm{y}} A\right)$ for both specifications. For this reason, the ratio of the design resistance to design strength for such a member becomes simply equal to the ratio of partial factor $\left(\gamma_{\mathrm{M}_{0}}=1.00\right)$ to the resistance factor $\left(\phi_{c}=0.90\right)$, i.e., to the value of 1.11 . This value drops slightly if the section has slender and Class 4 web (i.e., all I and HE sections listed in Table 2) since the effective area ratio $\left(A_{\mathrm{e}, \mathrm{EC} 3} / A_{\mathrm{e}, \mathrm{AISC} 360-16}\right)$ is smaller than unity for such sections as listed in Table 3 . On the other hand, the capacity ratios are slightly greater than 1.11 for members with slender and Class 4 flanges (i.e., HD sections listed in Table 2) since $A_{\mathrm{e}, \mathrm{EC} 3} / A_{\mathrm{e}, \mathrm{AISC} 360-16}$ ratio is larger than unity.

For all studied nonslender-element/non-Class 4 sections and steel grades, the capacity ratio curves increase slightly from 1.11 to approximately 1.13 with increasing slenderness ratio until the nondimensional slenderness becomes equal to 20. As mentioned previously, the reason for the increase in capacity in this region is the fact that while EC3 ignores,
AISC 360-16 considers flexural/torsional buckling effects in this region. After that, the capacity ratio curves decrease with increasing slenderness until they reach their minimum values. For members with a nonslender-element/non-Class 4 section, the minimum values of the capacity ratio depend on the buckling curve used in the calculation of design resistances: 1.10 for curve $a, 0.997$ for curve $b$, and 0.907 for curve $c$. It has been realized that the design buckling resistances of all studied I and HE members with slenderelement/Class 4 sections are computed using the buckling curve $b$. In many cases, the transitions to the basic curves occur at slendernesses smaller than those at which the minimum capacity ratio is attained. Even when the transitions occur at larger slendernesses, the value of 0.997 is found to decrease at most to 0.967 .

The values of the slenderness ratio at which the capacity ratios reach their minimum values depend on steel grade; as yield strength increases, it decreases slightly. For members with I or "large" HE sections, the mentioned slenderness ratio decreases from approximately 120 to 110 and 100 as the steel grade increases from S235 to S275 and S355. For members with "small" HE sections, the respective values of slenderness ratio are approximately equal to 115,110 , and 95. Since yield strength is not constant for all studied HD 
sections, the values of slenderness ratio at which the capacity ratio becomes minimum also depend on the flange thickness of the sections. For S275 steel grade, the mentioned slendernesses are observed to increase from 110 to 120 as the flange thickness increases. For S355 steel grade, this range changes from 95 to 105 . For S460 steel grade, the related slenderness ratios change from 90 to 95 for HD sections with $t_{\mathrm{f}}>100 \mathrm{~mm}$ and are equal to 95 for heavier HD sections.

After reaching minimum, capacity ratios increase with increasing slenderness. For all studied I- and HE-shaped members, the maximum values of the capacity ratios are found to be approximately 1.13, 1.15, and 1.17 for S235, S275, and S355 steel grades, respectively. These values occur at the largest member slenderness considered in the study. For HD-shaped members, the maximum capacity ratios are approximately 1.13 and 1.14 for S275 and S355 steel grades. As shown in Figure 13, these extremum values occur when nondimensional slenderness is equal to 20. For S460 steel grade, the maximum capacity is equal to 1.24 and occurs when the member slenderness is equal to 200 .

\section{Conclusions}

The design guidelines for structural steel buildings have just changed in Turkey. The Building Code for Steel Structures [1], which had been published in 1980 and based on allowable stress method, was replaced with the Specification of Design and Construction of Steel Structures (SDCSS) [3], which was prepared almost entirely based on the current American steel design specification (AISC 360-16) [2]. The use of Eurocode 3: Design of Steel Structures (EC3) [4], is also widespread in Turkey especially for steel structures constructed with the collaboration of Turkish and European design companies. This study aims to compare in detail the basic design guidelines given in both specifications. Since the scopes of both specifications are considerably wide, only the design guidelines defined for rolled I-shaped members subjected to axial compression are taken into consideration. Even though some studies in the literature have already compared the American and European steel design specifications, most of them examined only design buckling curves or compared design capacities for limited number of steel sections and grades. Furthermore, these studies typically excluded compression members with slender-element/ Class 4 sections and neglected the fact that the values given in both specifications for the elasticity modulus are different ( $E=200 \mathrm{GPa}$ in AISC $360-16$ whereas $E=210 \mathrm{GPa}$ in EC3). Moreover, the design rules given in AISC 360-16 for compression members with slender-element sections are completely different than those given in earlier version of the American steel design specifications (AISC 360-10 and AISC 360-05), and previous studies were conducted based on these earlier versions of the American specifications. In this study, design buckling resistances and design compressive strengths are computed for various European steel sections, member lengths, and steel grades. Among 153 sections examined in the study, 21 I- and HE-shaped sections are found to have slender and/or Class 4 webs when the steel grade is S355 and two HD sections are found to have slender and/or Class 4 flanges when the steel grade is $\$ 460$. In the study, the effective cross-sectional areas for these 21 sections are computed using both specifications and compared. In this way, the revised design guidelines given in AISC 360-16 for slender-element compression members are compared with those in EC3. For all sections, steel grades, and member lengths, the capacity ratios are also computed to compare the safety margins of the both design specifications. Limited to the studied sections, steel grades, and buckling lengths, the main findings of the study can be summarized as follows:

(i) Even though the definitions and limiting values for width-to-thickness ratios of compression elements vary in both documents, most of the sections classified as slender-element sections according to AISC 360-16 (SDCSS) are also classified as Class 4 sections according to EC3.

(ii) AISC 360-16 (SDCSS) treats a compression member which is originally classified to have a slender element section as a member with a nonslender-element section if its effective length is sufficiently long. This is quite realistic since, in both specifications, cross section classifications are done assuming that member buckling will not occur prior to local buckling. However, when the effective length of the member is sufficiently large, the member will buckle over its length at a stress much below the yield stress and before the buckling of its compression elements. In such cases, using effective cross-sectional area in capacity calculations will lead to the underestimation of the actual capacity of the member. In fact, a similar allowance for the treatment of Class 4 sections as non-Class 4 sections is also defined in Clause 5.5.2(9) in EC3; however, Clause 5.5.2(10) excludes the use of this allowance while computing the design buckling resistances. The authors of this study believe that the allowance given Clause 5.5.2(9) in EC3 resembles the "second check" done in AISC 360-16 (SDCSS) and recommend its use also in the calculation of buckling resistances for economical designs.

(iii) The smallest buckling lengths $\left(L_{c}^{*}\right)$ at which the sections that are originally classified as slender-element or Class 4 sections can be treated as nonslender-element/non-Class 4 sections are listed in the study. While determining $L_{c}^{*}$ values based on EC3, the maximum design compressive stress appearing in Clause 5.5.2(9) is determined from the design buckling resistance calculated assuming that the member has a non-Class 4 section for the considered buckling length and steel grade.

(iv) The effective cross-sectional areas computed using AISC 360-16 (SDCSS) are smaller than those computed using EC3 when the section has slender/ Class 4 webs and greater when the section has slender/Class 4 flanges. Nevertheless, the maximum difference between the computed values does not exceed $3 \%$. 
(v) The design values given in AISC 360-16 (SDCSS) for modulus of elasticity $(E)$ and shear modulus $(G)$ of structural steel are about 5\% smaller than those given in EC3. For this reason, even though comparison of design buckling curves is more general and easier, comparison of capacity ratio curves is more realistic.

(vi) For all studied steel grades and member lengths, the design compressive strengths computed for IPN and IPE sections, HEA and HEB sections with numbers equal to 400 or greater, and HEM sections with numbers equal to 340 or greater are either approximately equal to or smaller than the design buckling resistances. AISC 360-16 (SDCSS) gives conservative results also for HD sections with $\mathrm{S} 460$ steel grade. For other sections and steel grades, the design strengths can exceed the design resistances at moderate member slendernesses; however, the resistance-to-strength ratios (capacity ratio) do not fall below 0.907 in any case. In general, the capacity ratios reach their maximum values at the maximum member slenderness allowed by SDCSS $\left(L_{\mathrm{c}} / i=200\right)$. It is found that the capacity ratios can be as much as 1.24.

\section{Data Availability}

The data used to support the findings of this study are available from the corresponding author upon request.

\section{Conflicts of Interest}

The authors declare that there are no conflicts of interest regarding the publication of this paper.

\section{References}

[1] TSI, TS 648, Building Code for Steel Structures, Turkish Standard Institute, Ankara, Turkey, 1980.

[2] AISC, ANSI/AISC 360-16: Specifications for Structural Steel Buildings, American Institute of Steel Construction, Chicago, IL, USA, 2016.

[3] Ministry of Environment and Urbanisation, Specification for Design and Construction of Steel Structures, Republic of Turkey Ministry of Environment and Urbanisation, Ankara, Turkey, 2016.

[4] CEN, EN-1993-1-1, Eurocode 3-Design of Steel Structures, Part 1-1: General Rules and Rules for Buildings, European Committee for Standardization, Brussels, Belgium, 2005.

[5] R. Bjorhovde, "Evolution and state-of-the-art of column stability criteria," Journal of Civil Engineering and Management, vol. 16, no. 2, pp. 159-165, 2010.

[6] B. Bjorhovde, Deterministic and probabilistic approaches to the strength of steel columns, evolution and state-of-the-art of column stability criteria, Ph.D. dissertation, Lehigh University, Bethlehem, PA, USA, 1972.

[7] R. D. Ziemian, Guide to Stability Design Criteria for Metal Structures, John Wiley and Sons, Inc., Hoboken, NJ, USA, 6th edition, 2010.

[8] Y. Fukumoto and Y. Itoh, "Evaluation of multiple column curves using the experimental data-base approach," Journal of Constructional Steel Research, vol. 3, no. 3, pp. 2-19, 1983.
[9] E. S. Kameski, "Comparison of BS 5950 and AISC-LRFD codes of practice," Practice Periodical on Structural Design and Construction, vol. 3, no. 3, pp. 105-117, 2006.

[10] C. Topkaya and S. Şahin, "A comparative study of AISC-360 and EC3 strength limit states," International Journal of Steel Structures, vol. 11, no. 1, pp. 13-27, 2011.

[11] D. J. Yong, A. López, and M. A. Serna, "Beam-column resistance of steel members: a comparative study of AISC LRFD and EC3 approaches," International Journal of Structural Stability and Dynamics, vol. 11, no. 2, pp. 345-361, 2011.

[12] E. Maiorana and C. Pellegrino, "Comparison between Eurocodes and North American and main international codes for design of bolted connections in steel bridges," Journal of Bridge Engineering, vol. 18, no. 12, pp. 1298-1308, 2013.

[13] A. M. Gresnight, "Design rules for fillet welds in Eurocode 3 and AISC, Eurosteel 2014," in Proceedings of the 7th European Conference on Steel and Composite Structures, Naples, Italy, 2014.

[14] M. M. Bakhoum, S. A. Mourad, and M. M. Hassan, "Comparison of actions and resistances in different building design codes," Journal of Advanced Research, vol. 7, no. 5, pp. 757767, 2016.

[15] V. V. Galishnikova and T. H. Gebre, “A comparative study of beam design curves against lateral torsional buckling using AISC, EC and SP," Structural Mechanics of Engineering Constructions and Buildings, vol. 15, no. 1, pp. 25-32, 2019.

[16] T. V. Galambos, "A comparison of Canadian, Mexican and United States steel design standards," Engineering Journal, vol. 36, pp. 52-66, 1999.

[17] K. Loorits and I. Talvik, "Comparative study of the buckling of steel beams in Eurocode 3 and the Russian code," Journal of Constructional Steel Research, vol. 62, no. 12, pp. 1290-1294, 2006.

[18] C. Bernuzzi and B. Cordova, Structural Steel Design to Eurocode 3 and AISC Specifications, John Wiley \& Sons, Hoboken, NJ, USA, 2016.

[19] H. H. Snijder, L. G. Cajot, N. Popa, and R. C. Spoorenberg, "Buckling curves for heavy wide flange steel columns," Romanian Journal of Technical Science: Applied Mechanics, vol. 59, no. 1/2, pp. 178-204, 2014.

[20] CEN, EN 10025-2, Hot Rolled Products of Structural Steels-Part 2: Technical Delivery Conditions for Non-Alloy Structural Steels, European Committee for Standardisation, Brussels, Belgium, 2004.

[21] CEN, EN 10025-4, Hot Rolled Products of Structural Steels-Part 4: Technical Delivery Conditions for Thermomechanical Rolled Weldable Fine Grain Structural Steels, European Committee For Standardisation, Brussels, Belgium, 2004.

[22] Ministry of Environment and Urbanisation, Specification for Design and Construction of Steel Structures, Republic of Turkey Ministry of Environment and Urbanisation, Ankara, Turkey, 2018.

[23] CEN, EN-1993-1-5, Eurocode 3-Design of Steel Structures, Part 1-5: Plated Structural Elements, European Committee for Standardization, Brussels, Belgium, 2006.

[24] L. S. Da Silva, R. Simoes, and H. Gervasio, Design of Steel Structures, European Conventional for Constructional Steelwork (ECCS), Brussels, Belgium, 2nd edition, 2016. 